\title{
An Agent-Based Model-Driven Decision Support System for Assessment of Agricultural Vulnerability of Sugarcane Facing Climatic Change
}

\author{
Alina Evelyn Badillo-Márquez ${ }^{1}$, Alberto Alfonso Aguilar-Lasserre ${ }^{1, *} \mathbb{\infty}$, Marco Augusto Miranda-Ackerman ${ }^{2}{ }^{\infty}$, \\ Oscar Osvaldo Sandoval-González ${ }^{1}$, Daniel Villanueva-Vásquez ${ }^{3}\left(\mathbb{D}\right.$ and Rubén Posada-Gómez ${ }^{1}$ (i)
}

1 Division of Research and Postgraduate Studies, Tecnológico Nacional de México/Instituto Tecnológico de Orizaba, Av. Oriente 9, 852. Col. Emiliano Zapata, Orizaba 94320, Mexico; evelyn0712@gmail.com (A.E.B.-M.); osandoval@ito-depi.edu.mx (O.O.S.-G.); pgruben@yahoo.com (R.P.-G.)

2 Facultad de Ciencias Químicas e Ingeniería, Universidad Autónoma de Baja California, Tijuana 22390, Mexico; miranda.marco@uabc.edu.mx

3 Departamento de Investigación y Posgrado, Tecnológico Nacional de México/Instituto Tecnológico Superior de Misántla, Km 1.8 Carretera a lomas de Cojolite, Misántla 93821, Mexico; dany.villavas@gmail.com

* Correspondence: albertoaal@hotmail.com; Tel.: +52-(272)-725-7056

check for updates

Citation: Badillo-Márquez, A.E.;

Aguilar-Lasserre, A.A.;

Miranda-Ackerman, M.A.; Sandoval-González, O.O.;

Villanueva-Vásquez, D.;

Posada-Gómez, R. An Agent-Based

Model-Driven Decision Support

System for Assessment of

Agricultural Vulnerability of

Sugarcane Facing Climatic Change.

Mathematics 2021, 9, 3061. https:/ /

doi.org/10.3390/math9233061

Academic Editor: David Carfi

Received: 26 October 2021

Accepted: 24 November 2021

Published: 28 November 2021

Publisher's Note: MDPI stays neutral with regard to jurisdictional claims in published maps and institutional affiliations.

Copyright: (c) 2021 by the authors. Licensee MDPI, Basel, Switzerland. This article is an open access article distributed under the terms and conditions of the Creative Commons Attribution (CC BY) license (https:/ / creativecommons.org/licenses/by/ $4.0 /)$.

\begin{abstract}
In recent years, there have been significant changes in weather patterns, mainly caused by sharp increases in temperature, increases in carbon dioxide, and fluctuations in precipitation levels, negatively impacting agricultural production. Agricultural systems are characterized by being vulnerable to the variation of biophysical and socioeconomic factors involved in the development of agricultural activities. Agent-based models (ABMs) enable the study, analysis, and management of ecosystems through their ability to represent networks and their spatial nature. In this research, an $\mathrm{ABM}$ is developed to evaluate the behavior and determine the vulnerability in the sugarcane agricultural system; allowing the capitalization of knowledge through characteristics such as social ability and autonomy of the modeled agents through fuzzy logic and system dynamics. The methodology used includes information networks for a dynamic assessment of agricultural risk modeled by time series, system dynamics, uncertain parameters, and experience; which are developed in three stages: vulnerability indicators, crop vulnerability, and total system vulnerability. The development of $\mathrm{ABM}$, a greater impact on the environmental contingency is noted due to the increase in greenhouse gas emissions and the exponential increase in extreme meteorological phenomena threatening the cultivation of sugarcane, making the agricultural sector more vulnerable and reducing the yield of the harvest.
\end{abstract}

Keywords: agent-based modeling; agricultural vulnerability; climatic change; system dynamics; decision-support system; sugarcane vulnerability

\section{Introduction}

In Mexico, agricultural activities have a greater impact on the rural and industrial environment as it is the main source of income and food supplies through the exploitation of natural resources and positions itself as one of the main means of employment for the rural population [1].

Agricultural activities that heavily depend on the weather have a high vulnerability because of changes in climate patterns, mainly rainfall and extreme weather phenomena such as drought, extreme rain, hailstorms, and cyclones are having negative effects on agricultural activities causing the loss of crops globally and a decrease in food security [2]. The main impacts on the agricultural sector include, but are not limited to, severe damage to crops, soil erosion, inability to cultivate due to soil water saturation, adverse effects on water quality, water stress, and increased death of livestock [3]. Nevertheless, when speaking of the vulnerability of agricultural activities to climate change, not only extreme 
meteorological phenomena should be considered but also the expected environmental impacts such as incidence of forest fires, increase in pests and diseases, problems with water quality, and temperature variation; this results in lower crop yields caused by heat in warmer environments. As weather conditions change, the behavior of production areas should adapt to new changes and increasingly depend on the availability of water, mainly plants that do not have an irrigation system and are dependent on rainwater. An increase in the vulnerability rate among agricultural producers is therefore estimated due to the limited access to physical and material resources that make it possible to deal with environmental changes.

In this regard, agribusiness sugarcane has great potential for mitigating climate change through diversification in cogeneration and sustainable production of by-products as an effective means of curbing greenhouse gas emissions through the use of NPK (nitrogenphosphorus-potassium) fertilizers [4]. Global food production contributes $26 \%$ to greenhouse gas emissions, of which $7.02 \%$ is from crop production [5]. According to the Food and Agriculture Organization, pollutant emissions from agriculture in developing countries rose $32 \%$ between 1990 and 2005, and this trend is expected to continue to meet the demands of food products by a growing population.

The main objective of this study is an assessment of vulnerability to climate change in the agricultural sector through agent-based modeling $(\mathrm{ABM})$ by identifying socioeconomic and ecological variables to determine vulnerability and agricultural risk in the cultivation of sugarcane. The categorization of vulnerability is vital in decision making, allows determining the degree of vulnerability-risk existing in the system through the determination and identification of impact variables for the development of scenarios with effective adaptation measures to mitigate the impact. The purpose of the research is to assist in the decision-making process to maximize crop yields by generating work schemes that lead to the development of adaptation and/or mitigation actions to address climate change.

Agent-based models (ABMs) are characterized by their ability to analyze heterogeneous agents and their interactions to simulate emergent properties of the system [6]. The ABMs comprise several autonomous and independent virtual agents with their own goals [7]. The system under investigation is characterized by autonomous and independent agents (vulnerability indicator and crop yield agent), which transmit information to determine the vulnerability of the system (agent-total vulnerability of the system). While the flow of information handles virtual agents defined by variables that form information networks represented by models of the system dynamics and fuzzy logic. Based on the above, the research hypothesis is whether the development of the decision support system for the assessment of the agricultural vulnerability of sugarcane will allow the generation of alternative scenarios through an agent-based approach to minimize levels of vulnerability by means of the implementation of a reactive agent.

The sections that define this research are: Firstly, Background, this section shows the review of the literature on the impact of climate vulnerability in the agricultural sector. It then describes the methodology used in developing research based on intelligent agents and artificial intelligence techniques in Materials and Methods. In the Results and Discussion section, the research contributions are shown under the context of climate change in the sugarcane agricultural system. Finally, in the Conclusion section, the contribution of the proposed methodology to the identification of the critical variables of the system in the vulnerability assessment is mentioned.

\section{Background}

The effects of climate change on the agricultural supply chain have been compounded over the past 20 years by increasing demand for food and increasing population density. The expansion of arable land, pastures, plantations, and urban areas in the world, as well as the increase in the consumption of energy, water, and fertilizers, have led to changes in the land cover through the development of uncontrolled agriculture and the use of biofuels, which cause many environmental and socio-economic impacts such as greenhouse gas 
emissions, water availability, and pollution, deforestation, loss of biodiversity, loss of access to land [8].

The effects generated by climate change have had serious repercussions on the environment, mainly impacting agricultural systems. These impacts are mainly based on variations in variables such as temperature and precipitation levels. As a consequence, these variations have significant impacts on crops, with grain crops being the most affected by phenomena such as droughts and heat waves. The latter has the greatest impact on flowering, reproductive phase, and crop yields due to its influence on crop physiological processes such as pollination and photosynthesis at the soil level, generating crop losses; heat stress in crops indicates that even moderate increases in temperature reduce the yield of crops such as corn, beans, rice, and peanuts. High night temperatures can negatively influence crop yields. The incidence of weather events produces significant changes in crop yields, mainly affecting the economic sector of the agricultural supply chain [9-12].

Extreme weather events are recorded in Central America, which severely affect agriculture and rural livelihoods [13]. Government agencies have taken action to combat climate threats, such as implementing environmental policies to reduce uncertainty [14] through the management of agricultural resources [15]. Likewise, soil degradation [16] has a significant impact on agricultural activities and makes it impossible to reproduce plants, which is why it is necessary to develop soil management practices to reverse this problem [17].

Determining factors that increase risk requires a comprehensive analysis of the physical condition of the region, land use, biodiversity, and period [18,19]. Implementing agro-climate models enables the quantification of the impacts, the optimization of the management of agricultural practices, and predicting future trends in crop behavior $[10,20,21]$.

A vulnerability assessment system in an agricultural system that combines biophysical and socio-economic aspects was developed in western Austria [20]. The research aims to quantify the effects of the biophysical aspects (variability of climate change, soil, topography, and agronomic conditions). With the development and application of models to minimize the impact of the vulnerability in agriculture due to climate change, areas of improvement (fertilization, irrigation types, etc.) in agricultural production systems have been discovered to increase their profitability.

Within agricultural evaluation systems, decision support systems (DSS) play an important role in agricultural decision-making to improve agricultural productivity. [21] Developed a multi-criteria analysis where they evaluate and select the most suitable support system for sustainable agribusiness. The analysis was developed in fuzzy logic through the construction of linguistic variables modeled by fuzzy sets with the objective is to determine sustainable agricultural performance by analyzing three critical factors, including (i) the technology employed; (ii) organization including type and scale of farm and budget; and (iii) environment. The authors implemented the model developed in the Australian region, where agricultural productivity is threatened by increasing degradation of soil quality, increasing cost of nutrient inputs and land uses. In addition to the three critical factors mentioned above, the authors added criteria (iv) economic and (v) social. As a result of the research, it was shown that the technology factor offers a greater competitive advantage to maximize agricultural yield, therefore; the study provides an effective methodology for agricultural management evaluation.

In the evaluation of agricultural systems, resource limitation is a preponderant factor; [22] developed a model for planning the performance of irrigation systems in Turkey. The model estimates daily reference evapotranspiration values through models developed in deep learning-based gated recurrent units (GRUs) and tree-based models. The developed models consider meteorological variables such as maximum and minimum temperature, wind speed, relative humidity, dew point temperature, and duration of sunshine times. The models obtained determined that the maximum temperature was determinant in the estimation of evapotranspiration. 
Platforms powered by models based on agricultural information systems were developed using artificial intelligence to characterize and analyze climate vulnerability [23]. These models can estimate crop production and yield and quantify environmental variables such as water and nitrogen balances, organic substances, greenhouse gas emissions, etc. These models are supported by information systems based on vulnerability indicators to identify climate-relevant risks during the management of agricultural activity [24]. The agro-climatic indicators are generated through simulations of climatic conditions that represent impact variables that characterize the system (length of heatwaves, number of frost days, precipitation, and temperature). The results achieved make it possible to identify areas of opportunity that minimize the risks and impacts on agriculture in the face of climate change.

Models have been developed based on the distribution of climate classes and based on data on the biodiversity of the climate in a given area [25]. The data show a high level of bias. For this reason, it is necessary to use alternative sources of information to reduce the distortion. The modeling was carried out through the knowledge of the expert, with six categories defined to describe the diversity of the climate based on the influencing variables (temperature and precipitation) of the model to reduce the risk of bias during modeling.

Studies have been developed on the analysis of multi-agent systems for ecosystem management and found that the greatest advantage of agent-based modeling (ABM) is the combination of spatial nature and the ability to represent networks [26]. Benefits of implementing ABM include: (i) ability to couple social and environmental models, (ii) ability to examine environmental management strategies, and (iii) ability to model individual entities in decision making through their interactions; Therefore, the greatest challenge is to show that $\mathrm{ABMs}$ can provide new insights into the complex natural systems [6]. ABMs are typically used to model land use, land cover, and information exchange over networks that are integrated by agents on a larger or smaller scale; where the agents interact directly to weave every link within the network [27]. ABMs are used to create new models that adopt different approaches that include microeconomic models and empirical rules [28,29]. Implementing ABM integrates economic, social, and environmental components [30].

The methodologies analyzed in the background to address this problem are mostly integrated by models and information systems based on environmental indicators for the management of agricultural practices, characterization of biophysical aspects, and farm management, mainly. Among the techniques used for the development of these investigations are agroclimatic models developed through simulation and fuzzy logic with the objective of environmental characterization. The methodology developed in this research provides a macro-model based on ABM's that integrates experience and knowledge of the actors involved (fuzzy logic) and simulation of uncertain parameters and decision variables (system dynamics). The interaction of the techniques used above allows the communication of information networks made up of environmental and socioeconomic factors for the development of indicators that allow a dynamic and systemic study of the agricultural system under study.

The previous studies address the problem of climate change in agricultural systems under an environmental approach using modeling and simulation; however, the results of these approaches focus on the development of agroclimatic indicators constructed from climate simulations, handling socioeconomic factors as isolated factors, and in some cases, these are not considered in the modeling.

For this reason, the proposed systems in this research include an integral analysis of all the elements of the agricultural system under study, allowing an area of opportunity to comprehensively identify the behavior pattern of the agricultural system facing climate change. The present research proposes an agent-based model considering environmental, socioeconomic, and agricultural factors for the global integration of the agricultural system under study based on experience, knowledge and modeling the uncertainty of the system through fuzzy logic and system dynamics. Agent-based modeling offers the creation of new models at micro and macro levels that allow the evaluation of agricultural vulnerability 
and risk through scenarios of quantitative impacts generated by climate change to propose work schemes that lead to adaptation actions.

\section{Materials and Methods}

The following section describes the three primary stages of the methodology used in this work, as shown in Figure 1. In the first stage, the socio-economic and environmental variables that determine vulnerability and agricultural risk were identified. With the variables obtained, it is proposed to develop a model for assessing vulnerability in the agricultural sector using an agent-based modeling approach (ABM) called Agent Vulnerability Indicators, which comprises four networks developed by system dynamics. Each network includes information on land use, water resources, land value, and gas emissions. In the second stage, the Crop Agent is developed with the help of artificial intelligence techniques (fuzzy logic) to determine the vulnerability of the study crop (sugarcane). The flow of information between the agents of stages 1 and 2 then determines the global vulnerability of sugarcane in the agricultural sector (Stage 3).
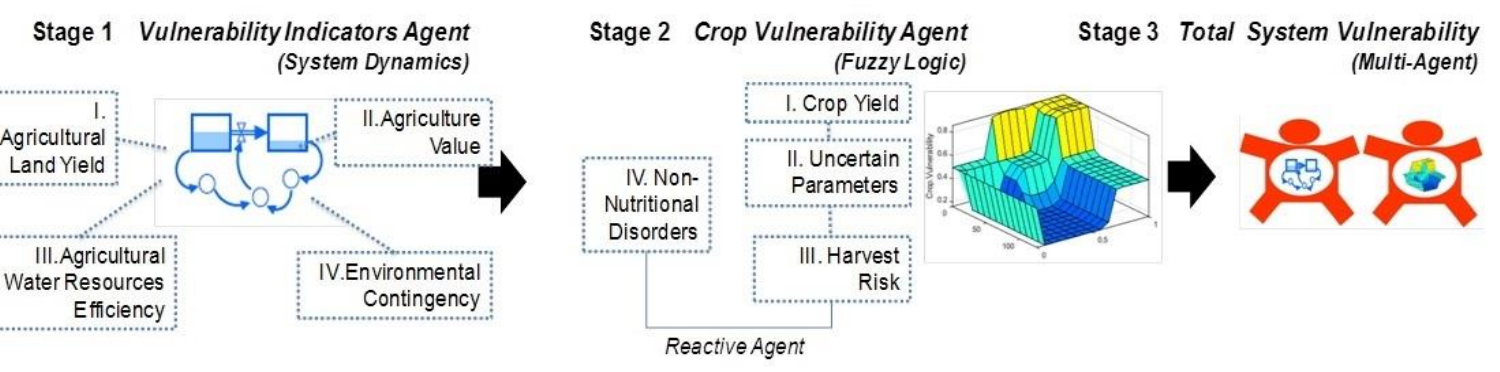

Figure 1. Methodology for determining total system vulnerability based on intelligent agents.

To achieve a better representation of the agricultural system, the developed model deals with complex representations for the decision-making process, considering risk, learning, and social interactions between agents. The multi-agent model, therefore, has a knowledge base which is composed of: (i) probability distributions which are defined by a database, and (ii) specialist knowledge.

According to the ABM approach, the agents that represent each of the stages of the multi-agent system are entities that demonstrate autonomy and proactivity (active agents). While passive entities are represented by each of the variables that integrate the information networks (sub-models of system dynamics and fuzzy logic). Table 1 describes the agents used in the multi-agent system and their major functions according to the classification of Yancato-Gurmán [31].

Table 1. Agent classification.

\begin{tabular}{ccc}
\hline Agent & Role & \multicolumn{1}{c}{ Activities } \\
\hline Vulnerability indicators & Active & $\begin{array}{c}\text { Models the behavior of networks to bring } \\
\text { information to the decision center. } \\
\text { It is in charge of decision-making when } \\
\text { modifying agricultural practices to } \\
\text { minimize vulnerability in the crop. } \\
\text { It provides a stimulus-response to } \\
\text { unexpected events in the system. }\end{array}$ \\
$\begin{array}{c}\text { Total system vulnerability } \\
\text { Information network variables } \\
\text { (population of agents) }\end{array}$ & Reactive & $\begin{array}{c}\text { Active } \\
\text { agents to determine the level of } \\
\text { vulnerability in the system. }\end{array}$ \\
\hline
\end{tabular}

Each of the stages of the methodology is described below. 


\section{Stage 1. Evaluation of vulnerability in the agricultural sector: Agent of Vulnerability Indicators}

The agent-based model (ABM) developed is a stochastic model in which the variables store and represent random quantities that are defined by probability distributions that change over time. The system dynamics methodology [32] enables the modeling and simulation of complex systems such as agricultural systems. This enables the behavior of the system to be simulated by feeding back information between the individual variables to understand and improve the interaction of their components [33].

For the modeling of the vulnerability indicator agent, the causal diagram was developed to represent the structure of the system and the flowchart that can simulate its behavior (Figure 2).

Agricultural Land Yield

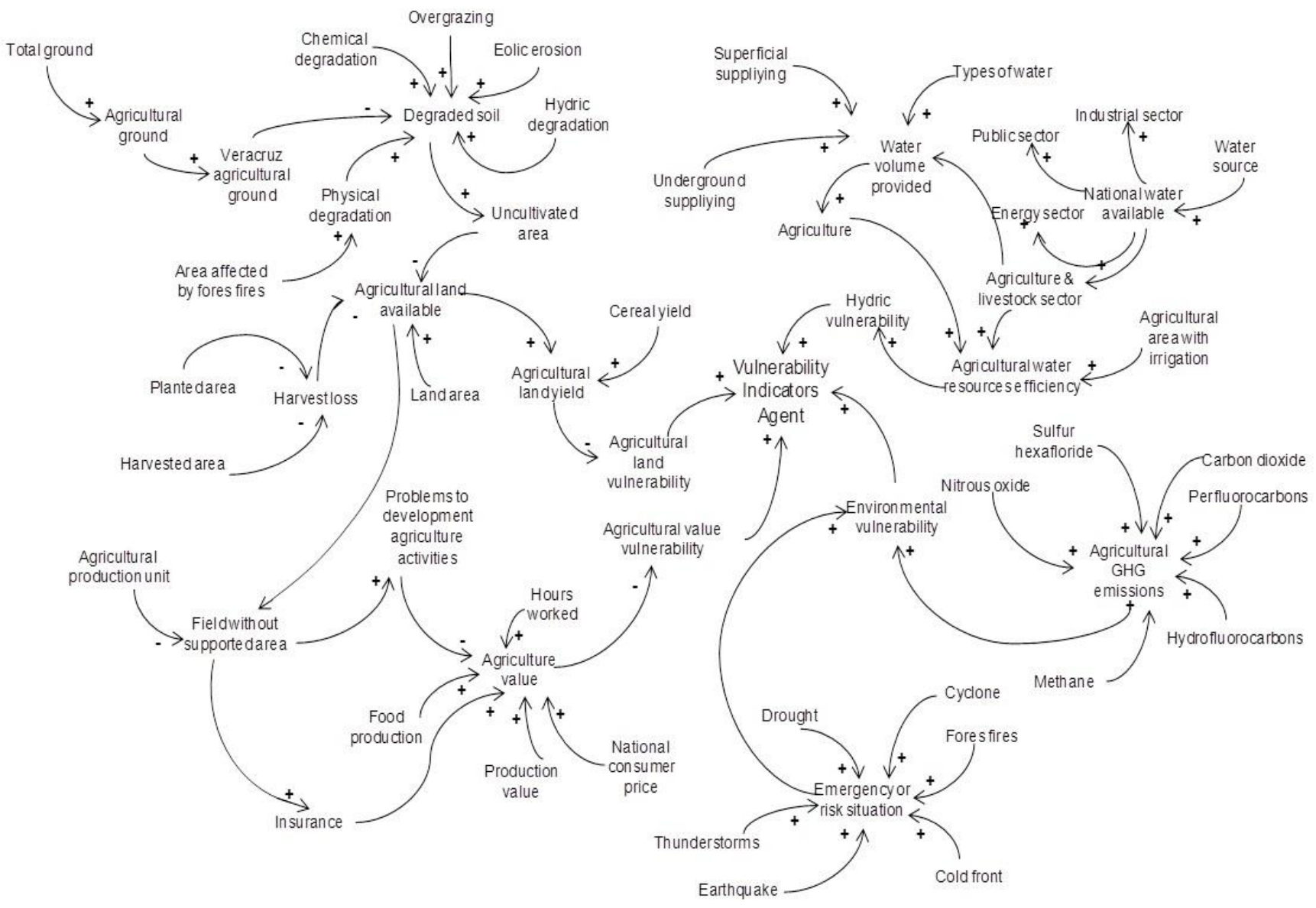

Agriculture Value

Agricultural Water Resources Efficiency 
productivity in the agricultural sector, problems in developing agricultural activities, the value of the harvest, hours worked and insurance for agricultural development.

The Agricultural water resources efficiency model enables the vulnerability of water resources in the agricultural sector to be estimated, as around 79\% of agricultural activities carried out in Mexico do not have an irrigation system [35]. The Environmental contingency model considers greenhouse gas emissions and serious environmental phenomena which, due to their frequency and magnitude, endanger the agricultural harvest.

The variables that feed the Vulnerability Indicator Agent model are modeled by probability distributions describing historical data for the period 2001-2018 [36-47].

Table 2 describes the main variables used in the models that make up the agent of the vulnerability indicators $[36,38,40,41,48-51]$.

Table 2. Variables of vulnerability indicators agent model.

\begin{tabular}{|c|c|c|}
\hline Variable & Definition & Units \\
\hline Agricultural Ground & Extension of agricultural land & $\mathrm{Ha}$ \\
\hline Total Ground & Extension of land in Mexican territory & $\mathrm{Ha}$ \\
\hline Area affected by Forest Fires & Extent of land affected by forest fires & $\mathrm{Ha}$ \\
\hline Physical Degradation & $\begin{array}{c}\text { Soil degradation caused by physical aspects: Compaction }(\mathrm{Fc}), \text { Loss of function and } \\
\text { productivity }(\mathrm{Fu}) \text {, Waterlogging }(\mathrm{Fa}) \text {, Decreased water availability }(\mathrm{Fd}) \text {, Embedding and } \\
\text { sealing }(\mathrm{Fe})\end{array}$ & На \\
\hline Chemical Degradation & $\begin{array}{l}\text { Chemical-originated soil degradation: Reduction of fertility and organic matter content } \\
\text { (Qd), Pollution (Qp), Salinization and/or alkalization (Qs), Eutrophication (Qe) }\end{array}$ & $\mathrm{Ha}$ \\
\hline Overgrazing & Agricultural area affected by intensive grazing for a long period & $\mathrm{Ha}$ \\
\hline Eolic Erosion & Surface wear due to wind & $\mathrm{Ha}$ \\
\hline Hydric Erosion & Segregation and sedimentation of water particles in the soil due to rain or surface runoff & $\mathrm{Ha}$ \\
\hline Uncultivated Area & Area unsuitable for agricultural activities due to severe or extreme degradation & $\mathrm{Ha}$ \\
\hline Planted/Harvested Area & Agricultural area planted and harvested & $\mathrm{Ha}$ \\
\hline Farmland & Extension of land available for cultivation & $\mathrm{Ha}$ \\
\hline Cereal Land & Extension of land for cereal production & $\mathrm{Ha}$ \\
\hline Crop Land & Extension of permanent land for cultivation & $\mathrm{Ha}$ \\
\hline Cereal Yield & Cereal yield per hectare harvested & $\mathrm{Kg} / \mathrm{Ha}$ \\
\hline Agricultural Land Yield & Agricultural area yield per hectare & $\mathrm{Kg} / \mathrm{Ha}$ \\
\hline Agricultural Production Unit & Agricultural statistical unit for measuring agricultural production in a given area & $\mathrm{m}^{2}$ \\
\hline Field Support Area & Agricultural area with some kind of support for carrying out agricultural activities & $\mathrm{Ha}$ \\
\hline Agricultural Problems & $\begin{array}{c}\text { Main problems for the development of agricultural activities, directly related to } \\
\text { the farmer }\end{array}$ & - \\
\hline Insurance & $\begin{array}{c}\text { Agricultural area with insurance for agricultural activities. It can have different types } \\
\text { of origin }\end{array}$ & $\mathrm{Ha}$ \\
\hline NCPI & $\begin{array}{c}\text { National Consumer Price Index, indicator to estimate the evolution of prices of } \\
\text { properties and services in Mexico }\end{array}$ & - \\
\hline Indexes & Indicator to estimate food production, hours worked, etc. & $\%$ \\
\hline GDP & Gross Domestic Product, base 2013 & MUS\$ \\
\hline Agriculture Value & Agricultural value added in relation to GDP & MUS\$ \\
\hline Water Source & $\begin{array}{c}\text { Origin of water according to its type of source: water well, storage, river, dam, spring, } \\
\text { open water well, etc. }\end{array}$ & $\mathrm{Hm}^{3}$ \\
\hline Water Supplying & Underground and superficial water supply & $\mathrm{Hm}^{3}$ \\
\hline National Water Availability & Volume of available water, which is distributed to various sectors & $\mathrm{Hm}^{3}$ \\
\hline Types of Water & $\begin{array}{l}\text { Volume of water according to its classification: white water, treated wastewater, } \\
\text { brackish water, raw sewage, etc. }\end{array}$ & $\mathrm{Hm}^{3}$ \\
\hline Water Efficiency & Efficiency of water resources for the development of agricultural activities & $\mathrm{Kg} / \mathrm{m}^{3}$ \\
\hline Emergency Risk Situation & $\begin{array}{c}\text { Natural events classified as a state of emergency or disaster which put agricultural } \\
\text { activities at risk. includes: forest fires, storms, cold front, frost, cyclones, } \\
\text { earthquakes, droughts }\end{array}$ & Events \\
\hline Agriculture GHG Emissions & $\begin{array}{c}\text { Greenhouse gases emissions (GHG) produced by the development of } \\
\text { agricultural activities }\end{array}$ & $\begin{array}{c}\mathrm{Gt} \\
\mathrm{CO}_{2} \mathrm{eq}\end{array}$ \\
\hline $\mathrm{CO}_{2}$ Emissions & $\begin{array}{c}\text { Carbon dioxide emissions; colorless, dense, non-reactive gas that is part of the closest } \\
\text { layer of the atmosphere to Earth }\end{array}$ & $\mathrm{CO}_{2} \mathrm{eq}$ \\
\hline $\mathrm{CH}_{4}$ Emissions & Methane emissions produced by the decomposition of organic matter & $\begin{array}{c}\mathrm{Gt} \\
\mathrm{CO}_{2} \mathrm{eq}\end{array}$ \\
\hline
\end{tabular}


Table 2. Cont.

\begin{tabular}{|c|c|c|}
\hline Variable & Definition & Units \\
\hline $\mathrm{N}_{2} \mathrm{O}$ Emissions & Nitrous oxide emissions are the main pollutant of the ozone layer & $\begin{array}{c}\mathrm{Gt} \\
\mathrm{CO}_{2} \mathrm{eq}\end{array}$ \\
\hline HFC Emissions & Hydrofluorocarbons are the third generation of refrigerant gases & $\begin{array}{c}\mathrm{Gt} \\
\mathrm{CO}_{2} \mathrm{eq}\end{array}$ \\
\hline PFC Emissions & $\begin{array}{l}\text { Perfluorocarbons are synthetic compounds containing fluorine and carbon atoms. They } \\
\text { are colorless gases that are not flammable at room temperature }\end{array}$ & $\mathrm{CO}_{2} \mathrm{eq}$ \\
\hline $\mathrm{SF}_{6}$ Emissions & $\begin{array}{l}\text { Sulfur hexafluoride is an inorganic compound that under normal conditions of pressure } \\
\text { and temperature is a non-toxic and non-flammable gas. } \mathrm{SF}_{6} \text { is five times heavier than air. }\end{array}$ & $\begin{array}{c}\mathrm{Gt} \\
\mathrm{CO}_{2} \mathrm{eq}\end{array}$ \\
\hline
\end{tabular}

Ton/Ha: tons per hectare; $\mathrm{m}^{2}$ : square meters; MUS\$: millions of dollars; $\mathrm{Hm}^{3}$ : cubic hectometer; $\mathrm{Kg} / \mathrm{m}^{3}$ : kilograms per cubic meter; $\mathrm{Gt} \mathrm{CO}_{2}$ eq: gigatons of carbon dioxide equivalent.

Table 2 shows the causal diagram of the Vulnerability Indicator Agent model. The relationships between the variables are represented by arrows accompanied by a positive $(+)$ or negative $(-)$ sign, indicating the type of influence one variable has on another. Positive relationships indicate that an increase or decrease in variable A has the same effect on variable B; Negative relationships indicate that an increase or decrease in variable A has an inverse effect on variable B [52].

\subsection{Formulation}

To formulate the model, predictions of the variables of interest were made and the equations for each subsystem were determined. To evaluate the behavior of the system over time, the trend of the time series used in the simulation model was determined. Table 3 shows the type of trend for each analyzed time series and the mathematical model used when $t>0$.

Table 3. Analysis of trend of vulnerability indicators agent.

\begin{tabular}{|c|c|c|}
\hline Time Series & Kind of Trend & Mathematical Model \\
\hline Total ground & No trend & 9299303 \\
\hline Agricultural ground & Downward & $69.17 \% 54.89<\%<73.38$ \\
\hline Area affected by fores fires & Upward & $f(t ; \mu, \sigma)=\frac{1}{t(0.242966) \sqrt{2 \pi}} e^{-(\ln (t)-349617)^{2} / 2(242966)^{2}}$ \\
\hline Land area & No trend & $12,578,2926$ \\
\hline Cereal yield & Downward & $f(t)=\frac{1}{754 \sqrt{2 \pi}} e^{-(t-2369)^{2} / 2(754)^{2}}$ \\
\hline Agricultural production unit & No trend & 20 \\
\hline Field support area; $\mathrm{Ha}$ & Upward & $f(t)=\frac{1}{8.81 E^{5} \sqrt{2 \pi}} e^{-\left(t-127.7 E^{5}\right)^{2} / 2\left(8.81 E^{5}\right)^{2}}$ \\
\hline Insurance application & Upward & $3.79 \% 3.15<\%<5.82$ \\
\hline Obtaining insurance & Upward & $9.48 \% 9.41<\%<9.67$ \\
\hline National Consumer Price Index & Upward & $f(t)=\frac{1}{34.9 \sqrt{2 \pi}} e^{-(t-69.43)^{2} / 2(34.9)^{2}}$ \\
\hline Inflation & No trend & $6.5 \%$ \\
\hline Productivity index & Upward & $f(t)=\frac{1}{2.47 \sqrt{2 \pi}} e^{-(t-99.85)^{2} / 2(2.47)^{2}}$ \\
\hline Hours worked index & Upward & $f(t)=\frac{1}{6.08 \sqrt{2 \pi}} e^{-(t-103.8)^{2} / 2(6.08)^{2}}$ \\
\hline Harvest index & Upward & $f(t ; \lambda, \mathrm{k})=\frac{3.01}{82.5}\left(\frac{\mathrm{t}}{82.5}\right)^{3.01-1} \mathrm{e}^{-\left(\frac{\mathrm{t}}{82.5}\right)^{3.01}}$ \\
\hline Food production index & Upward & $f(t ; \lambda, \mathrm{k})=\frac{2.6}{77.7}\left(\frac{\mathrm{t}}{77.7}\right)^{2.6-1} \mathrm{e}^{-\left(\frac{\mathrm{t}}{77.7}\right)^{2.6}}$ \\
\hline GDP (fourth quarter of 2018) & No trend & $18,512,407$ \\
\hline Production value index & Upward & $f(t)=\frac{1}{0.014 \sqrt{2 \pi}} e^{-(t-0.137)^{2} / 2(0.014)^{2}} * P I B P a$ \\
\hline Water availability for agricultural & No trend & $76 \%$ \\
\hline Underground suppliying(UndS) & Upward & $f(t ; \mu, \sigma)=\frac{1}{t(23.6) \sqrt{2 \pi}} e^{-(\ln (t)-504.8)^{2} / 2(23.6)^{2}}$ \\
\hline Superficial suppliying (SupS) & Upward & $f(t ; \mu, \sigma)=\frac{1}{t(162.4) \sqrt{2 \pi}} e^{-(\ln (t)-2383)^{2} / 2(162.4)^{2}}$ \\
\hline
\end{tabular}


Table 3. Cont.

\begin{tabular}{|c|c|c|}
\hline Time Series & Kind of Trend & Mathematical Model \\
\hline Planted Area & Upward & $f(t)=\frac{1}{1.41 E^{6} \sqrt{2 \pi}} e^{-\left(t-2.12^{7}\right)^{2} / 2\left(1.41 E^{6}\right)^{2}}$ \\
\hline Harvested Area & Upward & $f(t ; \lambda, \mathrm{k})=\frac{12.26}{1.97 E^{8}}\left(\frac{\mathrm{t}}{1.97 E^{8}}\right)^{12.26-1} \mathrm{e}^{-\left(\frac{\mathrm{t}}{1.97 E^{8}}\right)^{12.26}}$ \\
\hline Fores fires & Upward & $f(t)=\frac{1}{2204 \sqrt{2 \pi}} e^{-(t-7971)^{2} / 2(2204)^{2}}$ \\
\hline Drougth & Upward & $f(t)=0.004 e^{-0.004 t}$ \\
\hline Earthquake & Upward & $f(t)=0.004 e^{-0.004 t}$ \\
\hline Cyclone & Upward & $f(t)=0.003 e^{-0.003 t}$ \\
\hline Cold front & Upward & $f(t)=0.0085 e^{-0.0085 t}$ \\
\hline Thunderstorm & Upward & $f(t)=0.025 e^{-0.025 t}$ \\
\hline Cereal land & Downward & $f(t ; \lambda, \mathrm{k})=\frac{14.63}{0.08}\left(\frac{\mathrm{t}}{0.08}\right)^{14.63-1} \mathrm{e}^{-\left(\frac{\mathrm{t}}{0.08}\right)^{14.63}}$ \\
\hline Farmland & Downward & $f(t ; \mu, \sigma)=\frac{1}{t(0.012) \sqrt{2 \pi}} e^{-(\ln (t)-0.106)^{2} / 2(0.012)^{2}}$ \\
\hline Agricultural land & Downward & $f(t ; \mu, \sigma)=\frac{1}{t(0.021) \sqrt{2 \pi}} e^{-(\ln (t)-0.527)^{2} / 2(0.021)^{2}}$ \\
\hline Crop land & Downward & $f(t ; \mu, \sigma)=\frac{1}{t(0.0024) \sqrt{2 \pi}} e^{-(\ln (t)-0.010)^{2} / 2(0.024)^{2}}$ \\
\hline $\mathrm{CO}_{2}$ & Upward & $f(t)=13438 e^{-13438 t}$ \\
\hline $\mathrm{CH}_{4}$ & Upward & $f(t)=64986 e^{-64986 t}$ \\
\hline $\mathrm{NO}_{2}$ & Upward & $f(t)=32669 e^{-32669 t}$ \\
\hline Hydric erosion & Upward & $f(t)=$ Agricultural ground $* 0.119$ \\
\hline Eolic erosion & Upward & $f(t)=$ Agricultural ground $* 0.0949$ \\
\hline Overgrazing & Upward & $f(t)=$ Agricultural ground $* 0.028$ \\
\hline Physical degradation & Upward & $\begin{array}{c}f(t)=(\text { Agricultural ground } * 0.057)+ \\
\text { Area affected by fores fires }\end{array}$ \\
\hline Chemical degradation & Upward & $f(t)=$ Agricultural ground $* 0.1783$ \\
\hline
\end{tabular}

The agent model for vulnerability indicators has a period $(t>0)$ for 12 sugarcane harvest cycles and was developed in the Anylogic ${ }^{\circledR}$ Personal Learning Edition software (free software for student version) in the library for dynamic systems. Below is the mathematical formulation for the basic elements of the model where time series are used for its development.

(a) Degraded soil (DS). The variable is represented by the flow of variables: hydric erosion $(H E)$, wind erosion (WE), overgrazing $(O g)$, chemical degradation $(C D)$, and physical degradation $(P D)$.

$$
\frac{d D S}{d t}=D s_{t=1}+(H E+E E+O g+C D+P D)
$$

(b) Agricultural land available (AreaAgr), indicates the land that is available for the development of agricultural activities, except for the non-cultivable area due to soil degradation and the agricultural area with harvest loss due to weather events.

$$
\begin{aligned}
& \qquad \begin{aligned}
\frac{d \text { Area Agr }}{d t}=\text { AreaAgr } & \text { Area Available }) \\
& -\frac{d D S}{d t}+(\text { Planted Area }- \text { Harvested Area })
\end{aligned} \\
& \text { Area Available }=\text { Cereal Land }+ \text { Farmland }+ \text { Agricultural Land } \\
& + \text { Crop Land }
\end{aligned}
$$

(c) Field without supported area (FWSA). Area without government and/or private support for the development of agricultural activities.

$$
\text { FWSA }=\left(\frac{d A r e a A g r}{d t}-\text { Field support area }\right) * \text { Agricultural Production Unit }
$$


(d) Agricultural value (AgrValue). The total value of agriculture concerning GDP; includes time series food production index $(F P i)$, production value index $(P V i)$, harvest index $(H i)$, hours worked index $(H W i)$, national expected consumer price index (NCPIexp), productivity index $(P i)$ and the problems for the development of the agricultural activities index (PRi).

$$
\frac{d \text { AgrValue }}{d t}=\text { AgrValue }_{t=1}+(F P i+P V i+H i+H W i+N C P I \operatorname{lexp}+P i-P R i) * G D P
$$

(e) Hydric resources available (HyRes). Volume from different supply sources (well, river, spring, water dam, open-air water well, water bank, and other sources).

$$
\frac{d H y \text { Res }}{d t}=\text { HyRes }_{t=1}+\left(\frac{1}{9722 \sqrt{2 \pi}} e^{-\left(x-4.64 E^{5}\right)^{2} / 2(9722)^{2}}\right) 0.76
$$

(f) Water Resource Efficiency (WREff) indicates the efficiency of underground and surface water supply in the agricultural sector for the geographical area of the study case.

$$
\frac{d W R E f f}{d t}=W R E f f_{t=1}+\frac{\frac{d \text { HyRes }}{d t}}{\left[\left(\frac{1}{0.0272 \sqrt{2 \pi}} e^{-(x-0.7637)^{2} / 2(0.0272)^{2}}\right)(\text { UndS }+ \text { SupS })\right]}
$$

(g) Greenhouse gas emissions (GHG). Total greenhouse gas emissions from developing agricultural activities.

$$
\frac{d G H G}{d t}=G H G_{t=1}+\sum\left(S F_{6}+P F C+N_{2} \mathrm{O}+\mathrm{CO}_{2}+\mathrm{CH}_{4}+H F C\right)
$$

(h) Environmental Disasters (ED). Includes meteorological phenomena (drought, earthquake, cyclone, cold front, and thunderstorm) and forest fires that have been cataloged in a state of emergency or a disaster and endanger the safety of the harvest.

$$
\frac{d E D}{d t}=E D_{t=1}+\sum(\text { Emergency or risk events })
$$

\subsection{Implementation}

The Vulnerability Indicator Agent Model was developed in the Anylogic ${ }^{\circledR}$ software in the system dynamics library and is simulated throughout twelve cycles. The networks that incorporate vulnerability indicator agents are described below:

The network for available agricultural land makes it possible to estimate the main types of soil degradation in the agricultural sector and to determine the non-cultivable area. The available agricultural area is determined as a potentially arable area, whereby this strongly and extremely affected area is discarded. Thus, determining the performance and vulnerability of the agricultural area.

The agricultural value network values the agricultural area with the support of the field and activities with some kind of insurance for its development. The subsidies granted to the field are directly related to the specific characteristics of the farmers (age, gender, level of education, access to technology, etc). Therefore, the agent was assigned a logistic probability function based on the farmer's attributes. The lack of rural support for agricultural activity development is one factor that increases vulnerability to the value of agriculture. The level of vulnerability to the value of agriculture can then be estimated using the agricultural performance indices.

The agricultural water resource efficiency network is determined from the amount of water available to the agricultural sector from both underground and surface sources, as well as the agricultural area where an irrigation system is used.

The environmental contingency network comprises two modules. The first module determines the amount of GHG emissions from the agricultural sector. The second module makes it possible to estimate the amount of potentially hazardous weather events. 


\section{Stage 2. Development of the cultivation model: Sugarcane (Study case)}

106 crops are harvested in the state of Veracruz; with a production of 21,282,823.66 tons and a harvested area of 290,600.64 ha for 2018, sugarcane is the most harvested crop in the region [51]. The case study was developed in the coastal plain in the southern zone of the Sotavento plain in the Mexican state of Veracruz. Whose latitude and longitude are $18^{\circ} 36^{\prime} 35.8^{\prime \prime} \mathrm{N} 95^{\circ} 31^{\prime} 34.7^{\prime \prime} \mathrm{W}$.

Due to the continuity of the Los Tuxtlas mountain region, the soil is varied and has flat parts near the coast and on hills. It is a warm, regular climate with an average temperature of $25^{\circ} \mathrm{C}$; the average annual rainfall varies between $2000 \mathrm{~mm}$ and covers an area of 13,208 hectares.

The Simpson Crop Diversity Index was used to determine whether the study area might have agricultural vulnerability. $A_{t}$ represents the total harvested area in $\mathrm{Ha}, \mathrm{Nc}_{c}$ the total number of reported crops, $A j$ the sugarcane harvest in $H a$. The relationship between the Simpson crop diversity index and agricultural vulnerability is as follows: when the Simpson index is close to 1 , there is low vulnerability, because there are a high number of crops. Contrarily, because the index is close to 0 the vulnerability will be high due to the small number of crops.

$$
I d=1-\frac{\left(\sum_{i=1}^{N c} A j\right)^{2}}{A t^{2}}
$$

The index obtained is 0.7565 , which indicates that the approximate vulnerability of 0.32 is classified as low to moderate [48]. To determine the vulnerability of sugarcane production, the Crop Vulnerability Agent model was developed using fuzzy logic.

Figure 3 shows the methodology used.

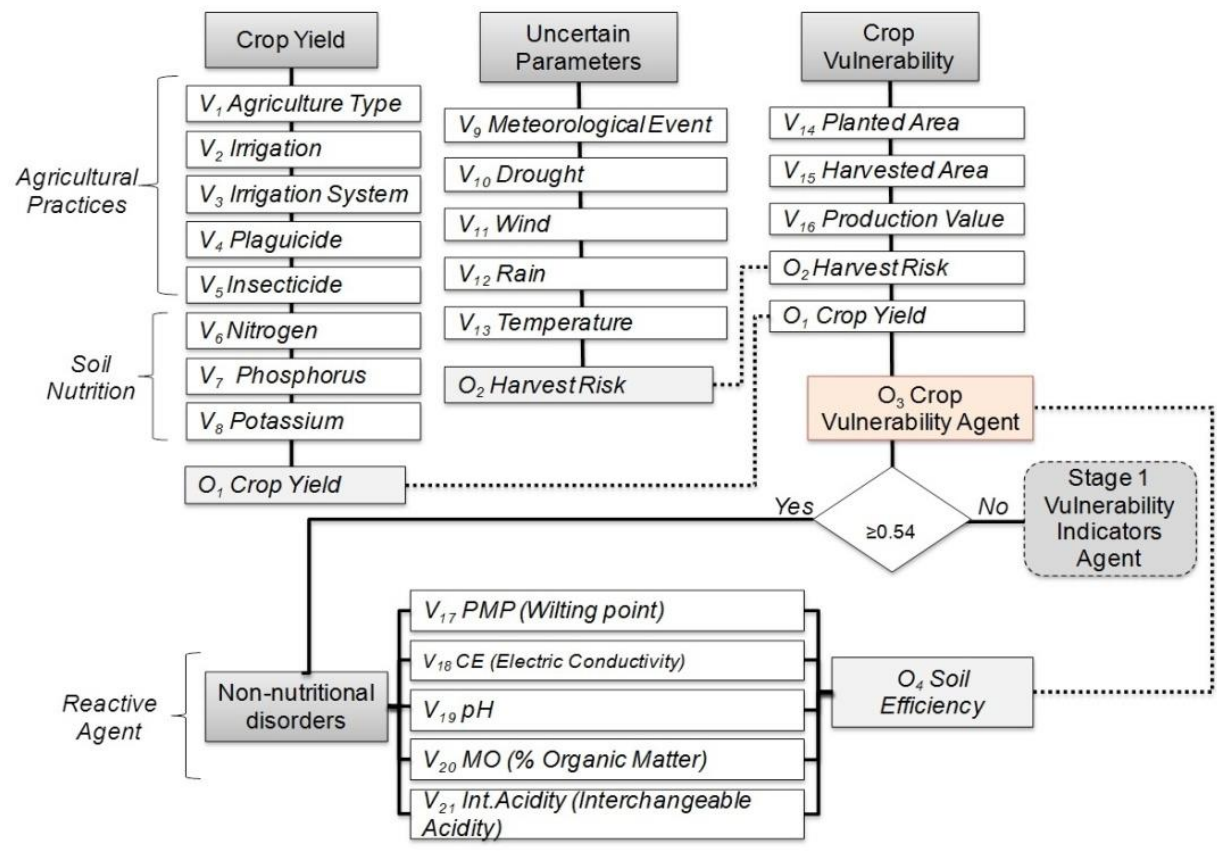

Figure 3. Crop vulnerability agent.

Agent-based modeling (ABM) makes it possible to propose different scenarios with active entities and to see what is happening in a problem, i.e., to examine the possible states of the system under investigation. ABMs are a proprietary artificial intelligence technology with the ability to emulate entities, processes, and uncertain flows in distributed environments where each entity makes a local decision based on its knowledge and behavioral patterns [7].

The Crop Vulnerability Agent model comprises three fuzzy logic models: crop yield, uncertain parameters, and crop vulnerability. The crop yield model determines the crop 
yield under optimal production conditions concerning agricultural practices and soil nutrition. The uncertain parameters model enables the modeling of uncontrollable variables related to climatological phenomena that affect agricultural production. The crop vulnerability model includes variables related to agricultural production. If the vulnerability is greater than or equal to 0.54 , it is assumed that there is a high vulnerability in agricultural production related to non-nutritional disorders as physical and chemical indicators of the edaphic environment related to precipitation and water storage capacity through the soil [53]. Otherwise, if the vulnerability of the crop is less than 0.54 ; the results obtained in stage 1 can be used to determine the overall vulnerability of the agricultural sugarcane production system.

Fuzzy logic models are designed in MatLab ${ }^{\circledR}$ using the Mamdani inference engine, which comprises membership functions for the twenty-one input variables and four output variables. Fuzzy logic is based on implementing linguistic variables for processing imprecise and fuzzy natural language, which comprises numbers and human expressions [54].

A linguistic variable takes on values with words that make it possible to describe the state of an object or phenomenon. These words can be represented by fuzzy sets [55]. Membership functions are used to define the value of the associated linguistic variable, i.e., they indicate the extent to which the linguistic variable belongs to the fuzzy set.

Figure 4 graphically describes the fuzzy sets corresponding to each linguistic variable of the developed fuzzy models.

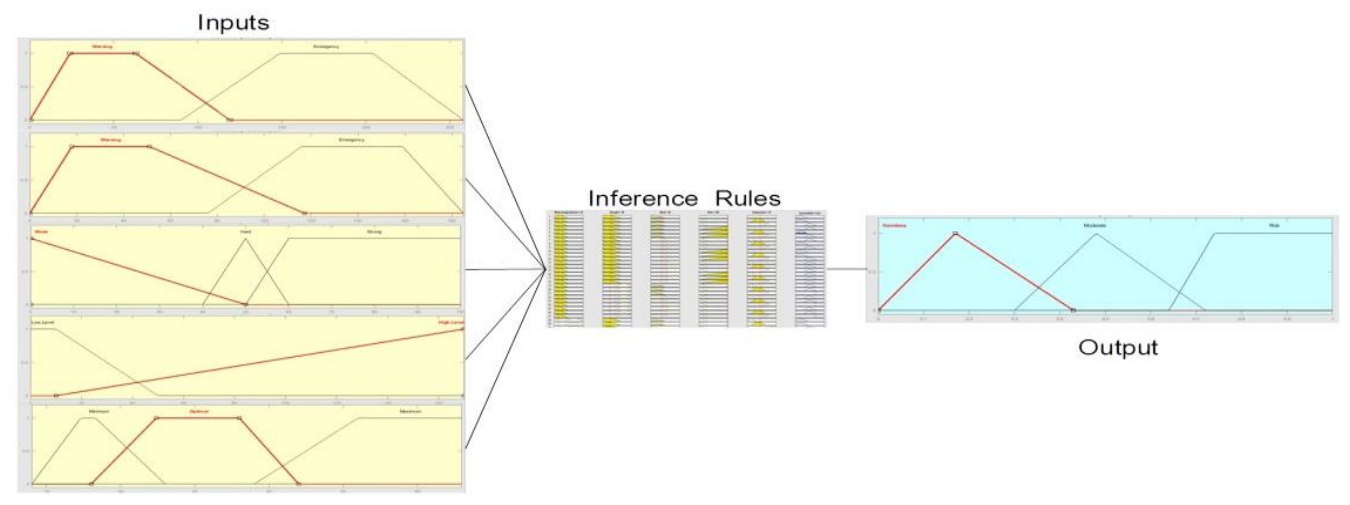

Figure 4. Graphic representation of fuzzy models.

The fuzzy sets for modeling the membership functions of the variables (input-output) are modeled by a triangular function (Tr) from three points and a trapezoidal function $(T)$ from four points. The functions that represent these equations are shown below:

$$
\begin{gathered}
\operatorname{Tr}(r ; a, b, c)=\left\{\begin{array}{cl}
0 ; & a<r \\
1-\left(\frac{b-r}{b-a}\right) ; & a \leq r \leq b \\
1-\left(\frac{r-b}{c-b}\right) ; & a \leq r \leq c \\
0 ; & c>r
\end{array}\right\} \\
T(t ; a, b, c, d)=\left\{\begin{array}{cl}
0 ; & t<a \\
1-\left(\frac{b-t}{b-a}\right) ; & a \leq t \leq b \\
1 ; \quad b \leq t \leq c \\
1-\left(\frac{t-c}{d-c}\right) ; & c \leq t \leq d \\
0 ; & t>d
\end{array}\right\}
\end{gathered}
$$

In the fuzzy logic process, the characterization of system behavior uses inference rules that are established through expertise and knowledge to characterize the behavior of the system [56]. The inference rules are based on the so-called fuzzy sets and a fuzzy inference 
system based on rules of the form IF-THEN, which are created using a Fuzzy Associative Memory (FAM) [57].

The FAM are matrices that represent the consequences of each rule defined for each combination of two or more inputs and enable a clear graphical representation of the relationships between two linguistic variables, input, and output variables. For this, all the possible combinations of rules with the input variables must be explicitly specified.

Table 4 describes the variables used in designing fuzzy logic models, and each of them indicates the unit of measurement and the type of variable (input or output) in the expert system $[4,54,58,59]$.

Table 4. Variables of sugar cane model.

\begin{tabular}{|c|c|c|c|c|}
\hline Variable & Definition & Units & \multicolumn{2}{|c|}{ Input Outpu } \\
\hline $\mathrm{V}_{1}$ Agriculture Type & Modality in which agricultural activities are carried out: open or protected & Mode & I & \\
\hline $\mathrm{V}_{2}$ Irrigation & $\begin{array}{l}\text { Water mode used in the development and reproduction of the crop: rainfall } \\
\text { or irrigated }\end{array}$ & Mode & $\mathrm{I}$ & \\
\hline $\mathrm{V}_{3}$ Irrigation System & Irrigation system used: gravity, canal, sprinkler, trickle or pipeline & Mode & I & \\
\hline $\begin{array}{l}\mathrm{V}_{4} \text { Plaguicida, } \\
\mathrm{V}_{5} \text { Insecticide }\end{array}$ & $\begin{array}{l}\text { Agricultural practices for the control of pests that affect the crop. The control over } \\
\text { these becomes a determinant to ensure agricultural production }\end{array}$ & Application & $\mathrm{I}$ & \\
\hline $\mathrm{V}_{6}$ Nitrogen, & Variables refer to soil nutrition; which is an agricultural practice which is used to & $\mathrm{Kg} \mathrm{ha}_{-1}$ & I & \\
\hline$V_{7}$ Phosphorus, & supply nutrients to the soil and the roots of the sugarcane, with the aim of & $\mathrm{Kg} \mathrm{P}_{2} \mathrm{O}_{5}$ ha -1 & I & \\
\hline $\mathrm{V}_{8}$ Potassium & maximizing production yields and crop quality & $\mathrm{Kg} \mathrm{K} 2 \mathrm{O}$ ha-1 & $\mathrm{I}$ & \\
\hline $\mathrm{O}_{1}$ Crop Yield & Ratio of total production of a certain crop harvested per hectare & Ton/Ha & & $\mathrm{O}$ \\
\hline $\begin{array}{l}\text { V9 Meteorological } \\
\text { Events }\end{array}$ & $\begin{array}{l}\text { Hydro meteorological phenomena declared as a state of "emergency" endangering } \\
\text { the safety of the crop }\end{array}$ & Events & I & \\
\hline $\mathrm{V}_{10}$ Drought & $\begin{array}{l}\text { Events with lack of rain for a prolonged period of time producing dryness in } \\
\text { agricultural fields and water shortages }\end{array}$ & Events & $\mathrm{I}$ & \\
\hline $\mathrm{V}_{11}$ Wind & Uncertain event directly affecting crop yield and quality & $\mathrm{Km} / \mathrm{hr}$ & $\mathrm{I}$ & \\
\hline $\mathrm{V}_{12}$ Rain & Uncertain event which in turn provides the water for the crops & $\mathrm{mm} / \mathrm{month}$ & I & \\
\hline $\mathrm{V}_{13}$ Temperature & $\begin{array}{l}\text { Uncertain parameter representing the physical magnitude that reflects the amount of } \\
\text { heat in the environment }\end{array}$ & ${ }^{\circ} \mathrm{C}$ & $\mathrm{I}$ & \\
\hline $\mathrm{O}_{3}$ Harvest Risk & Interaction of climatic parameters to determine risk in the crop & Risk Level & & $\mathrm{O}$ \\
\hline $\mathrm{V}_{14}$ Planted Area & Agricultural area on which the crop seed is deposited & Ton & $\mathrm{I}$ & \\
\hline $\mathrm{V}_{15}$ Harvested Area & Agricultural area on which production of the desired crop was obtained & Ton & I & \\
\hline $\mathrm{V}_{16}$ Production Value & Monetary value obtained from the sale of agricultural production & $\begin{array}{l}\text { Thousands of } \\
\text { US\$ }\end{array}$ & $\mathrm{I}$ & \\
\hline $\mathrm{O}_{3}$ Crop Vulnerability & $\begin{array}{l}\text { Grade to which the crop may be adversely affected by the interaction of } \\
\text { physicochemical factors, agricultural practices, climatic phenomena, etc. }\end{array}$ & Vulnerability Le & evel & $\mathrm{O}$ \\
\hline $\begin{array}{l}\mathrm{V}_{17} \text { Wilting point } \\
\text { (PMP) }\end{array}$ & $\begin{array}{l}\text { Minimum moisture point at which a plant can no longer extract water from the soil } \\
\text { and cannot recover from water loss even if the ambient humidity is saturated }\end{array}$ & PMP Level & $\mathrm{I}$ & \\
\hline $\begin{array}{c}\mathrm{V}_{18} \text { Electric } \\
\text { Conductivity }(\mathrm{CE})\end{array}$ & Measures the concentration of soluble salts present in the soil solution & $\mathrm{dS} / \mathrm{m}$ & I & \\
\hline $\mathrm{V}_{19} \mathrm{pH}$ & Measurement to determine the degree of alkalinity or acidity present in soil & pH Level & I & \\
\hline $\begin{array}{l}\mathrm{V}_{20} \text { Organic Matter } \\
(\mathrm{MO})\end{array}$ & $\begin{array}{l}\text { Heterogeneous compound formed by the accumulation of partially or completely } \\
\text { decomposed materials of animal and/or plant origin }\end{array}$ & $\%$ & $\mathrm{I}$ & \\
\hline $\begin{array}{l}\mathrm{V}_{21} \text { Interchangeable } \\
\text { Acidity (Int.Acidity) }\end{array}$ & $\begin{array}{l}\text { Amount of exchangeable hydrogen ions per fraction of organic matter in the soil to } \\
\text { determine the amount of improvers for optimum } \mathrm{pH}\end{array}$ & $\mathrm{cMol}^{*} \mathrm{Kg}^{-1}$ & I & \\
\hline $\mathrm{O}_{4}$ Soil Efficiency & $\begin{array}{l}\text { Water storage capacity of the soil based on physicochemical indicators of the } \\
\text { soil environment }\end{array}$ & Efficiency Level & & $\mathrm{O}$ \\
\hline
\end{tabular}

\section{i. Development of the fuzzy logic model to predict crop yield: sugarcane}

The crop yield model makes it possible to predict the behavior of the crop concerning the quantity produced (harvest) per plot used (sown area). The model is fed by eight input variables that describe the type of agriculture used (open sky or protected), the type of irrigation (temporary or watering), and the management of agricultural practices to control the occurrence of pests and diseases affecting the crops as well as the nutrition of the soil by providing the necessary NPK (nitrogen-phosphorus-potassium) nutrients to maximize crop yields [53] and the irrigation system used (gravity, channels, sprinkler, drip or pipe).

\section{ii. Development of the fuzzy logic model of uncertain parameters to predict harvest risk}

Characterizing the sugarcane production system is important to control or predict the behavior of variables that affect crop yield and to model uncertain parameters that may interfere with crop production. The uncertain parameters model increases the relationship 
of uncontrolled variables that may be present in sugarcane production and that have a positive or negative impact on that performance. These uncertain parameters mainly include the variable "meteorological events" such as cyclones, hurricanes, tropical storms etc., that have been declared in a state of emergency or "disaster" that could have negative consequences on the sugarcane production system. The variable "drought" mainly affects the fertility of agricultural soils.

The variables "wind", "rain" and "temperature" are the prevailing hydro climatological conditions for the development and growth of the crop; these variables represent the uncertain parameters. Uncertain parameters help predict crop productivity behavior and determine harvest risk (output variable). The inference rules are validated by open data provided by government agencies $[4,36,58,60]$.

iii. Development of the fuzzy logic model to predict the vulnerability of the crop: sugar cane

The crop vulnerability model determines the level of vulnerability of agricultural sugarcane production to assess the adaptive capacities and increase the resilience of the agricultural production system. The model is fed with historical data for the period 2001-2018 of sugarcane production, the output variables of the crop yield, and uncertain parameter models. The rules have been validated using historical open data from the agricultural sugarcane production system in the state of Veracruz $[4,58,59,61]$.

iv Development of the fuzzy logic model of non-nutritional disorders to predict the efficiency of the cultivation soil (Reactive Agent)

The model of diffuse non-nutritional disorders assumes the role of a reactive agent. Its function is to respond to stimuli from the environment in which it is located [62]. If the vulnerability score is $\geq 0.54$ and the vulnerability is rated Medium to High, the reactive agent will be activated. The relationship of the reactive agent model to crop vulnerability is that the higher the soil efficiency, the lower the vulnerability. Non-nutritional disorders are indicators of edaphic status and the risk of waterlogging in the agricultural sector [63]. The rules are validated by the expertise of the results obtained from previous research on geographical and edaphic information on precision agriculture of sugarcane in Mexico [53].

Appendix A describes the parameters used when designing the networks: input variables, the structure of fuzzy sets (linguistic labels and intervals), knowledge base (inference rules), and output variables.

\section{Results}

This section presents the results of the development of the agent-based model (ABM). Where the major benefits stand out: (i) a combination of social and environmental models; (ii) Management of environmental aspects and (iii) Modeling of information networks, which are composed of individual entities that serve as decision-making aids. The properties to consider in the ABMs depend on the goal and focus of the agent. Therefore, the decision-making process is adaptable to the characteristics and perspectives of the model. The ABM simulation was carried out for a twelve-cycle analysis of sugarcane cultivation.

\section{Stage 1: Results obtained from the dynamic models (Agent vulnerability indicators)}

The vulnerability indicator is viewed as an empirical model because (i) there is uncertainty, (ii) information networks are comprising databases, and (iii) emerging phenomena are considered. Emerging phenomena are properties of the system and not of individual agents; therefore, they cannot be examined in isolation [64]. Furthermore, one disadvantage of ABMs is their ability to get complex easily, which is why a sensitivity analysis must be performed to validate them. According to Forrester and Senge [65], system dynamics models can be tested and validated through dimensional consistency and extreme conditions.

(a) Dimensional consistency is used to analyze whether equations and time series are correctly connected. In this case, the output values of the sub-models use kilograms per hectare $(\mathrm{kg} / \mathrm{Ha})$ to determine the yield of the agricultural crop; kilograms per cubic meter $\left(\mathrm{kg} / \mathrm{m}^{3}\right)$ to measure the efficiency of water resources in the agricultural sector; Millions of dollars 
(USD) to determine the value of agriculture concerning GDP, and gigatons of carbon dioxide equivalent (Gt CO2eq) to measure the amount of greenhouse gas emissions emitted by the agricultural sector. To standardize the output values of the networks for the vulnerability, a factor on a scale of 0 to 1 has been assigned. 1 is the highest vulnerability value.

(b) Extreme conditions make it possible to identify errors in the model structure and to analyze the behavior of different scenarios given possible variations. For the analysis under extreme conditions, the critical variables of the system were modified: available national water, available agricultural land, greenhouse gas emissions, and emergency or risk situation. The sensitivity analysis of water availability can estimate the production of water resources under different scenarios over time. The value of agriculture and the yield of agricultural land can be visualized through a sensitivity analysis of the availability of agricultural hectares. The greenhouse gas emissions and the increase in hydrometeorological events because of climate change enable the environmental vulnerability to be assessed. The variations were made through a sensitivity analysis of five scenarios that projected the value of the registered trend for 2018. The projections of the scenarios were made: eliminating the trend $(-100 \%)$, halving the trend $(-50 \%)$ followed the current trend without modifications $(0 \%)$, and for trend increases $(+50 \%$ and $+100 \%)$. The sensitivity analysis was carried out in the Stella ${ }^{\mathrm{TM}}$ software.

Table 5 shows the values that were obtained after performing the sensitivity analysis. As observed for a decrease in trend $(-100 \%$ and $-50 \%)$, the values obtained when simulating the critical variables are lower; this can be detrimental to water resource efficiency and available agricultural land and can make the system more vulnerable. Likewise, a reduction in GHG emissions and the presence of risky events help reduce vulnerability. Contrarily, an increase in the trend (50\% and $100 \%)$ has a positive effect on the development of agricultural activities due to the use of water resources and land use. However, this has a negative impact on the environment. A sensitivity analysis, therefore, makes it possible to observe the behavior and dynamics of the system, which gives validity and robustness.

Table 5. Values of interest variables for each simulated scenario.

\begin{tabular}{cccccc}
\hline Variable & $\begin{array}{c}\text { Value } \\
\text { Trend }\end{array}$ & $\begin{array}{c}-\mathbf{1 0 0} \% \\
\text { Trend }\end{array}$ & $\begin{array}{c}\text { Trend } \\
(0 \%)\end{array}$ & $\begin{array}{c}50 \% \\
\text { Trend }\end{array}$ & $\begin{array}{c}100 \% \\
\text { Trend }\end{array}$ \\
\hline $\begin{array}{c}\text { Agricultural water resources } \\
\text { efficiency }\end{array}$ & 1.34 & 1.51 & 1.69 & 1.88 & 2.06 \\
Agricultural land available & $4,896,459$ & $5,496,168$ & $6,095,876$ & $6,695,585$ & $7,295,293$ \\
GHG emissions & 70,397 & 121,396 & 172,396 & 223,395 & 274,394 \\
Emergency or risk situation & 4808 & 6371 & 7935 & 9498 & 11,061 \\
\hline
\end{tabular}

Figure 5A shows the effects of the variable National Available Water $\left(\mathrm{Hm}^{3}\right)$ on the behavior of the Agricultural water resources efficiency network $\left(\mathrm{kg} / \mathrm{m}^{3}\right)$ over a validation period of twelve cycles. Scenarios 1 and 2 show a decrease in the trend, scenario 3 the current trend, and scenarios 4 and 5 show an increase in the trend.

When validating the networks for agricultural yields and agricultural values, the trend of the Total ground variable was changed, as an increase or decrease in this variable has a direct effect on the variable "available agricultural land" (Figure 5B). The sensitivity analysis shows a decrease in scenarios 1 and 2 given the decrease in the trend, while an increase in the trend increases the value achieved in scenarios 4 and 5 . For the estimation of the available agricultural land, the resulting non-cultivable area is excluded. The environmental contingency network comprises two critical variables: greenhouse gas emissions and emergency or risk situations. Emissions from the agricultural sector contribute around $12 \%$ to total greenhouse gas emissions at the national level (INECC). The Intergovernmental Panel on Climate Change (IPCC) classifies the national inventory of emissions by chemical compounds for the main environmental items, divided into categories and sectors [66]. 

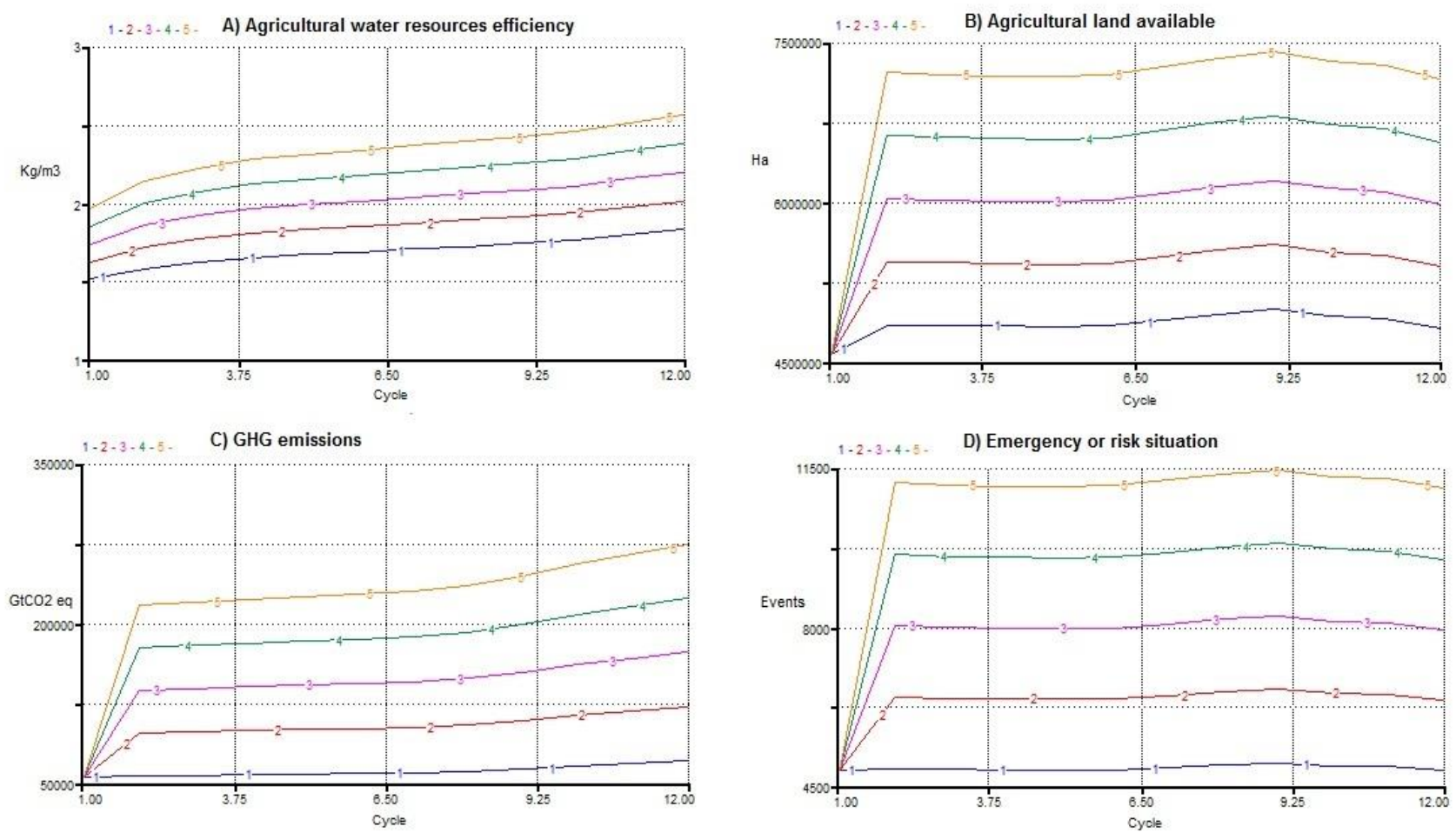

Figure 5. Sensitivity analysis of critical variables.

The emissions are divided into six greenhouse gases contained in the Kyoto Protocol: carbon dioxide, methane, nitrous oxide, hydrofluorocarbons, perfluorocarbon, and sulfur hexafluoride [67]. For the variable emergency or risk situation, the number of events within this classification that were reported by the National Center for Disaster Management (CENAPRED) was counted. Figure 5C,D show the results obtained in the sensitivity analysis for twelve culture cycles.

The efficiency of water resources depends on the volume of water available. The agricultural sector accounts for around $76 \%$ of the national water volume. The efficiency of water resources in Mexico averages $1.45 \mathrm{~kg} / \mathrm{m}^{3}$ for the years 1994-2016, with 2012 being the year with the highest yield of $1.86 \mathrm{~kg} / \mathrm{m}^{3}$ [40]. Figure $6 \mathrm{~A}$ shows the behavior of the efficiency of the water resources concerning the water volume.

As can be seen, as the availability of water for the development of agricultural activities increases, the efficiency of water resources increases in the same way. Following the historical trend, an increase in the trend in water availability can be observed through simulation cycles; However, the efficiency of water resources remains semi-constant (cycles 10-12), which is because a decrease in crop yield has been observed.

The projected results for twelve growth cycles following the current trend of the system are shown below (Figure 6B). As can be seen, an increase in the yield per hectare cultivated increases the value of agriculture. The most promising scenario is in cycle 4 with $3806.64 \mathrm{~kg} / \mathrm{ha}$ and $\$ 740,404.64$ million. The GDP value achieved in the fourth quarter of 2018 was used to project the agricultural value variables [68].

It can be seen, that in Scenarios 1 and 2, when the trend decreases, GHG decreases, and there are fewer incidents that put agricultural harvests at risk. Conversely, if the trend increases, environmental contingency will increase. The sensitivity analysis based on the causal diagram (Figure 2) shows the expected behavior in the sub-model, why it can be concluded that the network vulnerability indicator agent is robust and valid. Figure $6 \mathrm{C}$ shows the results of simulating twelve crops of the critical variables of the environmental contingency network. The expected value is affected by the projection of historical data trends from 2001 to 2018. With the results obtained, an exponential increase is observed in both time series. The increase in the GHG emissions variable at the end of the simulation 
shows an increase of $21.5 \%$. The increase in total emissions from the agricultural sector is determined by the source emissions from methane, nitrous oxide, and carbon dioxide [42]. The trend of risk or emergency events is between $9 \%$ and $11 \%$ between the individual cycles. However, this number is expected to continue to increase due to changes in climatological factors, which could have a significant impact on crop safety for some regions in Mexico.
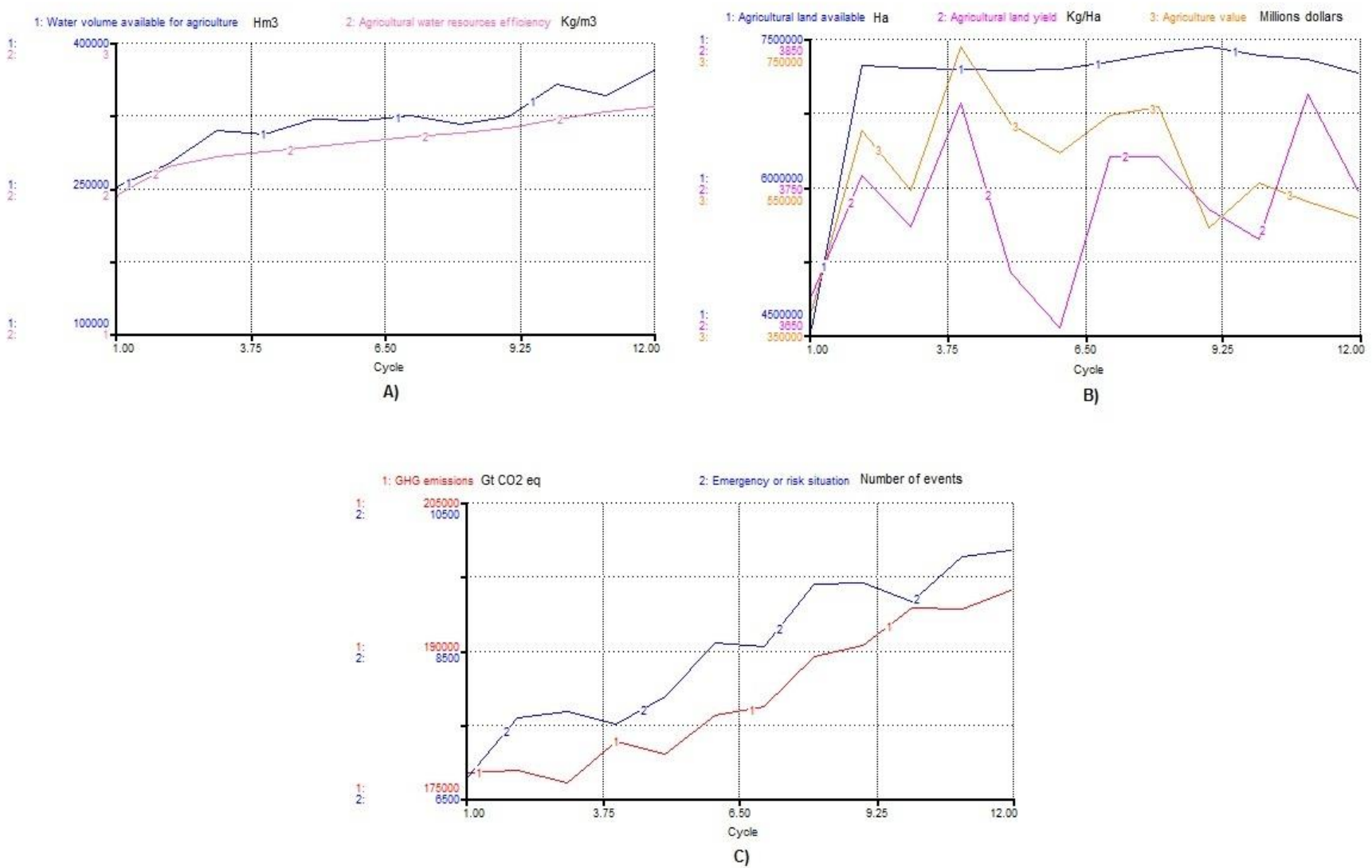

Figure 6. Projection of variables.

Table 6 shows the results of the variables of interest during the twelve-cycle simulation. The data for the agricultural value variable is expressed in millions of dollars using the exchange rate as a reference and the percentage of GDP relative to the fourth quarter of 2018.

Table 6. Values of interest variables for each simulated cycle.

\begin{tabular}{|c|c|c|c|c|c|c|c|c|}
\hline \multirow{3}{*}{ Cycle } & \multicolumn{8}{|c|}{ Variables } \\
\hline & \multirow{2}{*}{$\begin{array}{c}\text { Water Volume } \\
\text { Available } \\
\mathrm{Hm}^{3}\end{array}$} & \multirow{2}{*}{$\begin{array}{c}\text { Water } \\
\text { Resources } \\
\text { Efficiency } \\
\mathrm{Hg} / \mathrm{m}^{3}\end{array}$} & \multirow{2}{*}{$\begin{array}{c}\text { Land } \\
\text { Available } \\
\text { Ha }\end{array}$} & \multirow{2}{*}{$\begin{array}{c}\text { Land Yield } \\
\qquad \mathrm{Kg} / \mathrm{Ha}\end{array}$} & \multicolumn{2}{|c|}{ Agricultural Value } & \multirow{2}{*}{$\begin{array}{c}\text { GHG } \\
\text { Emissions } \\
\text { Gt } \mathrm{CO}_{2} \mathrm{eq}\end{array}$} & \multirow{2}{*}{$\begin{array}{c}\text { Emergency or } \\
\text { Risk Situation } \\
\text { Events }\end{array}$} \\
\hline & & & & & Mill US\$ & $\%$ GDP & & \\
\hline 1 & $251,773.89$ & 1.45 & $7,227,184.35$ & 3676.06 & $18,743.80$ & 2.060 & $159,964.05$ & 6774.44 \\
\hline 2 & $273,972.29$ & 1.64 & $7,206,865.98$ & 3757.75 & $30,735.37$ & 3.379 & $166,960.44$ & 7570.99 \\
\hline 3 & $309,046.29$ & 1.71 & $7,190,620.79$ & 3722.91 & $26,778.92$ & 2.944 & $173,457.32$ & 7660.92 \\
\hline 4 & $304,838.15$ & 1.75 & $7,182,446.01$ & 3806.64 & $36,383.52$ & 4.000 & $177,753.08$ & 7493.91 \\
\hline 5 & $321,256.42$ & 1.79 & $7,195,389.17$ & 3691.39 & $31,181.25$ & 3.428 & $176,422.15$ & 7866.49 \\
\hline 6 & $319,024.29$ & 1.82 & $7,275,353.99$ & 3653.58 & $29,259.90$ & 3.216 & $180,710.70$ & 8598.80 \\
\hline 7 & $324,990.54$ & 1.85 & $7,362,793.28$ & 3770.19 & $31,747.40$ & 3.490 & $179,379.77$ & 8547.41 \\
\hline 8 & $315,145.00$ & 1.88 & $7,425,284.69$ & 3770.10 & $32,340.86$ & 3.555 & $183,372.56$ & 9395.35 \\
\hline 9 & $324,001.19$ & 1.92 & $7,333,854.86$ & 3734.56 & $24,244.44$ & 2.665 & $184,259.85$ & 9408.19 \\
\hline 10 & $356,892.50$ & 1.97 & $7,295,293.55$ & 3714.15 & $27,219.68$ & 2.992 & $189,287.81$ & 9151.24 \\
\hline 11 & $345,194.27$ & 2.02 & $7,157,878.98$ & 3802.90 & $25,964.10$ & 2.854 & $190,470.86$ & 9767.92 \\
\hline 12 & $371,708.19$ & 2.06 & $7,103,162.95$ & 3747.27 & $24,884.65$ & 2.735 & $194,315.76$ & 9857.86 \\
\hline
\end{tabular}




\section{Stage 2: Results obtained from the fuzzy models}

The input parameters for each variable represent the data reported by the industrial sugar mill to the case study. Once the parameters have been introduced into the fuzzy model, the diffusion process converts the fuzzy parameters of the input variables through the values of the degree of membership of the fuzzy sets into a numerical value for the output variable and for activating inference rules Appendix B describes the input parameters for each fuzzy model.

The value for the sugarcane yield in the fuzzy model is 65.1 tons/ha, a value that is considered to be moderate to high in terms of vulnerability. This value may indicate that the soil is deficient in N-P-K nutrients or that pests and diseases are affecting the crops. Figure 7 shows a comparison of the historical data reported by the Information Service for Agriculture and Fisheries (SIAP) for the last 12 cycles with the results of the fuzzy model.

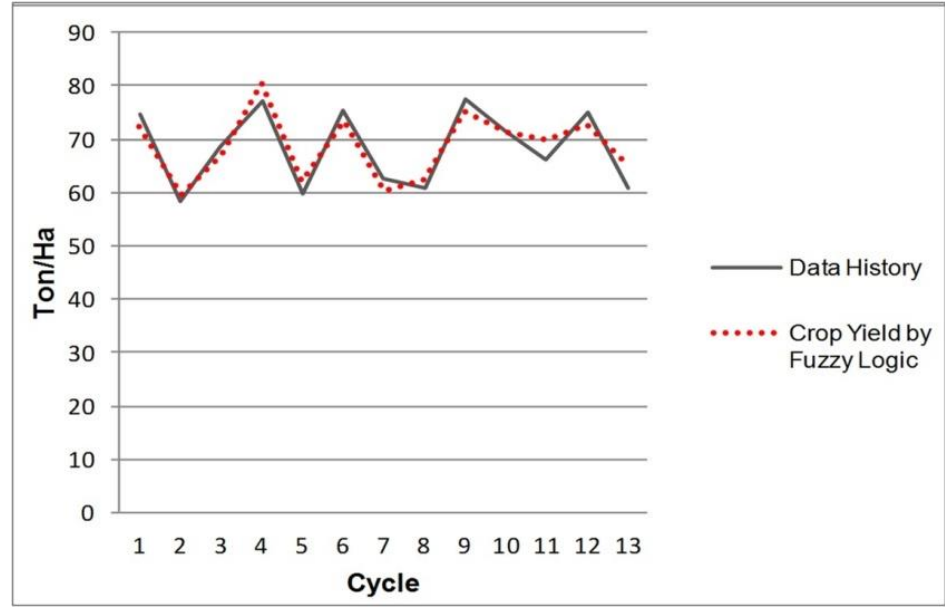

Figure 7. Sugar cane yield: data history-VS-fuzzy logic model data.

The results obtained in Figure 7 show a correlation between the data obtained by the fuzzy model and the historical data given for the sugarcane yield. The correlation coefficient obtained is $94.65 \%$. The results presented below (Figure 8 ) show the response surfaces that were obtained with a higher cultivation yield. The highest expected yield varies between 76 and 81 tons/ha in terms of the variables N-P-K (nitrogen, phosphorus, and potassium) related to soil nutrition. Using fertilizers is crucial for the productivity of the plantations. Using fertilizers provides the nutrients that are deficient in agricultural soils due to soil degradation or the effects of climate change. Using fertilizers prevents the loss of nutrients through leaching and counteracts the effects of saline solution that inhibit root growth.

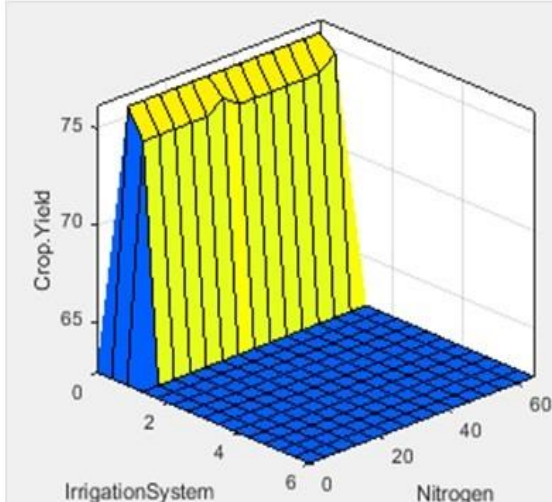

A

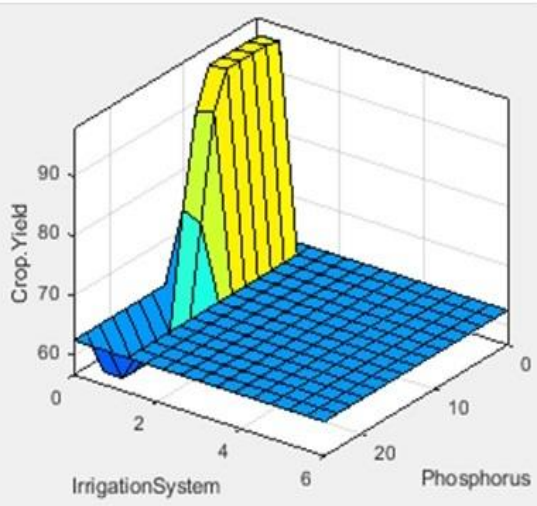

B

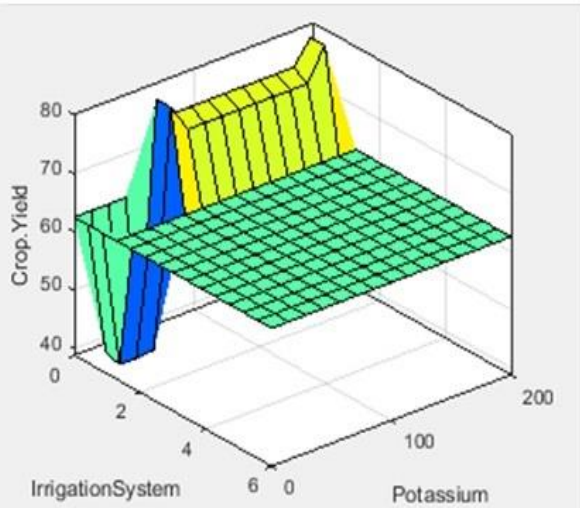

C

Figure 8. Impact of input variables in crop yield model. 
The addition of nitrogen $(\mathrm{N})$ is important in the formation of plant material (sprouts) and can stimulate the intensive growth phase (Figure 8A). Lack of nitrogen can cause premature leaf death and leaf blade discoloration. The highest expected value of the crop yield is related to the addition of phosphorus (P) (Figure $8 \mathrm{~B}$ ), as this is required in larger proportions during the development phase of the crop but if the recommended values are exceeded (>Extreme weather events are recorded in Central America, which severely affect agriculture and rural $15 \mathrm{~kg} \mathrm{P}_{2} \mathrm{O}_{5} \mathrm{ha}^{-1}$ ). It reduces the yield, the sugar concentration, the sucrose content in the juice, and the purity of the culture [4]. Potassium $(\mathrm{K})$ increases the yield of the stems and the sugar concentration in the cane, a potassium deficiency reduces the accumulation of sugar in the stems, degrading the quality of the crop (Figure 8C). As observed in the response surfaces, there is no interaction with the variable "irrigation system" since sugarcane is produced under rainy conditions. The most suitable medium for plant growth is when the rainfall regime is around $1500 \mathrm{~mm}$, considering that the plant uses $50-100 \mathrm{~m}^{3}$ of water to produce one ton of sugarcane (fresh weight). Based on the 2017 National Agricultural Survey (ENA) report, it was found that $80 \%$ of agricultural sugarcane producers had no problems with water for cultivation, so there was no need to introduce an irrigation system.

The result after the diffusion process is a harvest risk of 0.21 , which is classified as low risk and is categorized under the "harmless" linguistic label. Figure 9A shows the interaction of the variables that may increase the harvest risk, with a value of up to 0.85 being considered high risk. Temperature is one factor that is highly related to the growth of the plantation. It has optimal values between 25 and $38^{\circ} \mathrm{C}$. Values outside this range have a negative effect on the regrowth or germination of sugarcane. Values above $38^{\circ} \mathrm{C}$ reduce the photosynthesis process of the culture and alternate the sucrose concentration. Besides the temperature, wind speed is a decisive factor that increases the risk of harvesting. In agricultural areas with strong winds, water loss is high due to rapid evaporation from the soil surface. Winds at speeds over $60 \mathrm{~km} / \mathrm{h}$ destroy the vegetation by losing leaves due to the mechanical effect they have on the sugarcane.

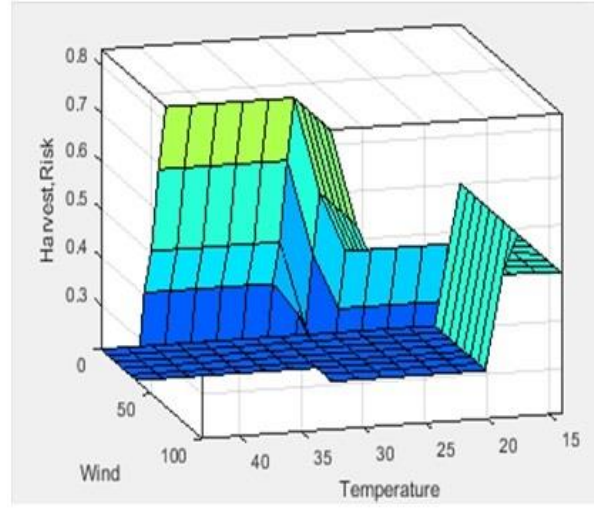

A

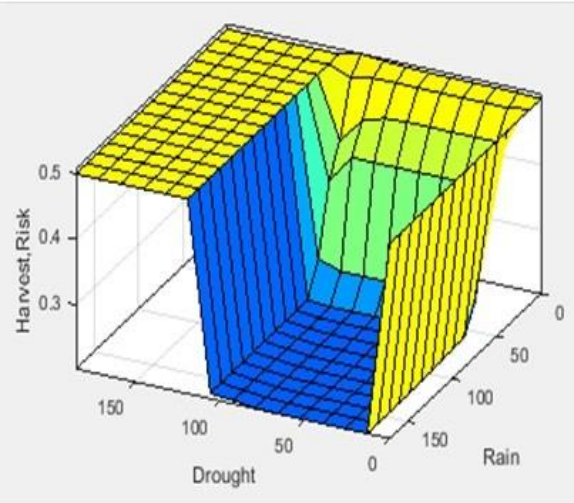

B

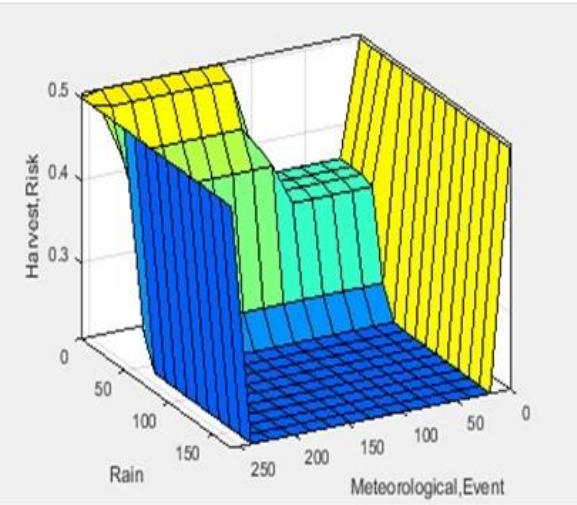

C

Figure 9. Impact of input variables in uncertain parameters model.

The water requirement during sugarcane growth is higher compared to most crops, between 50 and $70 \%$ of the roots are distributed in the first $30 \mathrm{~cm}$ depth. This is the area where nutrients and water are more absorbed. During periods of drought, when conditions of low humidity prevail, the roots of the crop tend to grow deeper and look for water resources. This will cause the water to be mainly concentrated in the roots, and less concentrated in other parts of the plant, thereby reducing the production capacity of the crops. Figure 9B shows the relationship between drought and rain variables, where the observed risk level is higher than 0.45 , which is considered a "moderate to high" risk.

Hydrometeorological phenomena are usually accompanied by gusts of wind above $120 \mathrm{~km} / \mathrm{h}$ and torrential rainfall, which increases the risk of harvest due to the mechanical 
action exerted on the crop. Figure $9 \mathrm{C}$ shows the relationship of the variables rain and meteorological events, in which an incidence of over 160 events with an emergency declaration and precipitation over $100 \mathrm{~mm}$ is observed, whereby the harvest risk is increased to a "moderately high" level.

The proportion of events in the study region concerning those reported at the national level is approximately $23.74 \%$; however, in 2004, 2010, and 2013 there was an increase due to hydrometeorological events with a declaration of "disaster", according to reports from the National Center for Civil Protection (CENAPRED).

These events are related to extremely atypical rainfall (2004), heavy rainfall from Hurricane Karl and Cyclone Mathew (2010), and tropical storms: Barry, Fernando, Manuel, and Hurricane Ingrid (2013).

Figure 10 shows a history of the hydrometeorological events reported in Mexico in the period 2001-2016 [36]. The percentage of events recorded in the Tabasco-Veracruz state region.

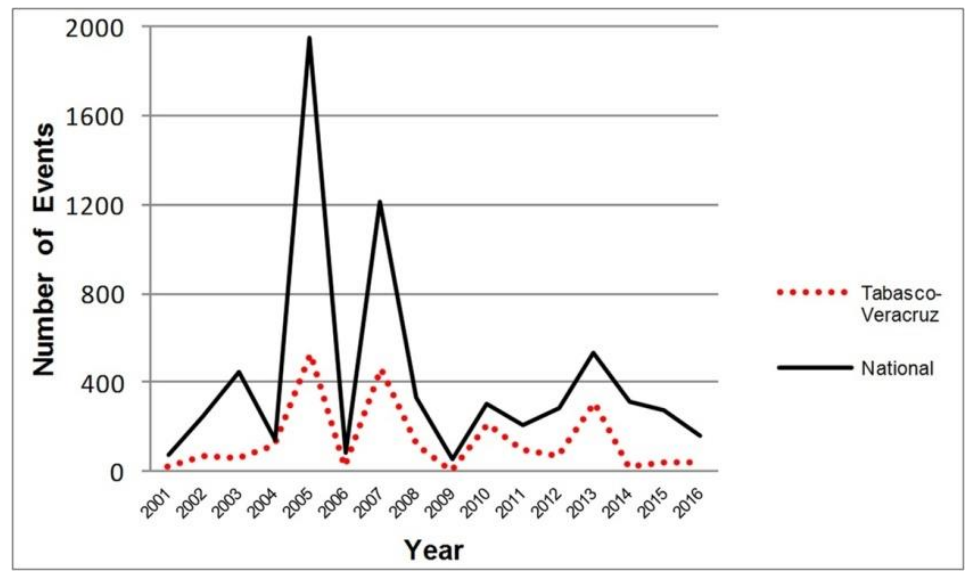

Figure 10. Number of hydrometeorological events reported in México in the period 2001-2016.

With the results of the fuzzy models (crop yield and harvest risk) and the data on agricultural sugarcane production (cultivated area, harvested area, and production value), the degree of vulnerability of the crop was determined through the diffuse crop vulnerability model. The vulnerability of the crop obtained is 0.265 ("low-medium" level). Mexico has 55 sugar mills, of which Veracruz has 20. This makes Mexico the state with the highest sugar production nationwide (2,620,194 tons). The observed yield from sugar production is related to changes in climatic conditions caused by global warnings, such as changes in rainfall and extreme weather events, which adversely affect agricultural production and increase the risk of harvesting.

Figure 11A shows the relationship between the variables crop yield and harvest risk. An increase in vulnerability is observed in the results obtained in the response area, increasing the risk of harvesting and reducing the yield per hectare.

With the increasing impact of climate change, there is a need to develop strategies to increase productivity and maximize the potential of the agro-food sector. The relationship between the yield of sugarcane production (harvested area) is not proportional; Although the planted area is large, it does not ensure that the expected crop yield will be the same (Figure 11B), but mainly depends on various factors related to good management of agricultural practices and climatic factors. One of the major challenges facing the sugar sector is the global supply of sugar due to increasing competition in the sweetener manufacturing market. Therefore, the sugarcane agribusiness strives to increase profitability and sustainability to ensure a quality offer with competitiveness in the market and to maintain a stable production value. Figure $11 \mathrm{C}$ shows the relationship between production value and crop yield. 


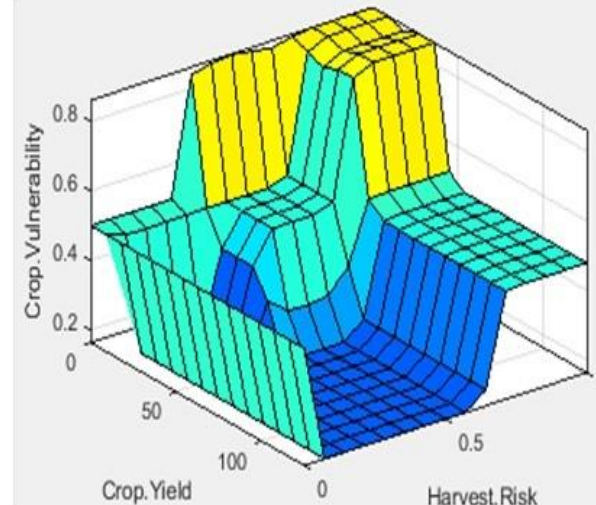

A

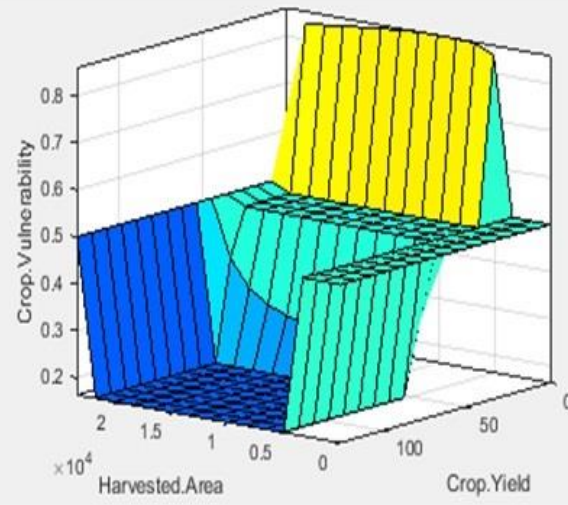

B

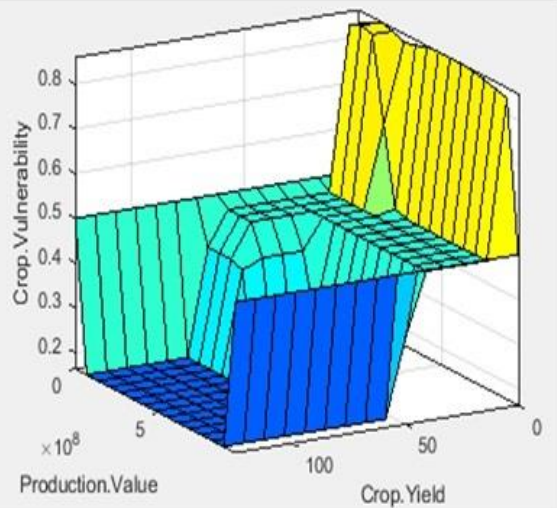

c

Figure 11. Impact of input variables in crop vulnerability model.

The agricultural supply chain is affected by climate change, and the socio-economic changes in agricultural production demand due to fluctuations in food and net import demand have reduced agricultural production efficiency $[69,70]$. On the other hand, in the medium term, the uncertainty of Mexico's geographic location and the scale and frequency of extreme events may greatly increase the vulnerability of the agricultural sector [45]. Faced with the increased vulnerability of sugarcane production, proper management of the physicochemical indicators of the edaphic environment can increase the yield of sugarcane per hectare. The non-nutrition disorders model has the function of a reactive agent because it can model the physicochemical indicators of the edaphic condition of the sugar mill supply area to predict the efficiency of agricultural soil. So it helps to resist the vulnerability of crops. Through the fuzzy model, agricultural soil efficiency of 0.783 ("average optimal") was obtained.

The main soils of the agricultural land are Vertisole, Gleysole, Cambiosole, and Lithosole. The former is characteristic soils that are very hard and tend to create deep cracks during periods of drought. Gleysols are soils that tend to accumulate water during periods of higher rainfall. Cambisols and lithosols are soils that are very prone to erosion.

The results obtained in the response surfaces show a higher efficiency $(\approx>0.77)$, which results from the interaction of the variables organic matter and $\mathrm{pH}$ (Figure 12A).

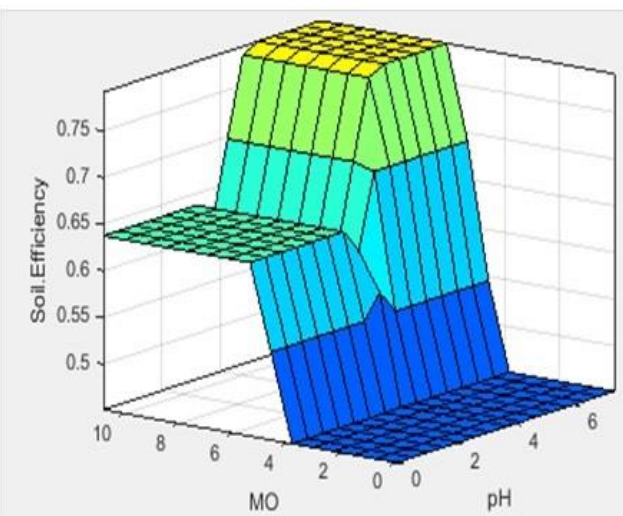

A

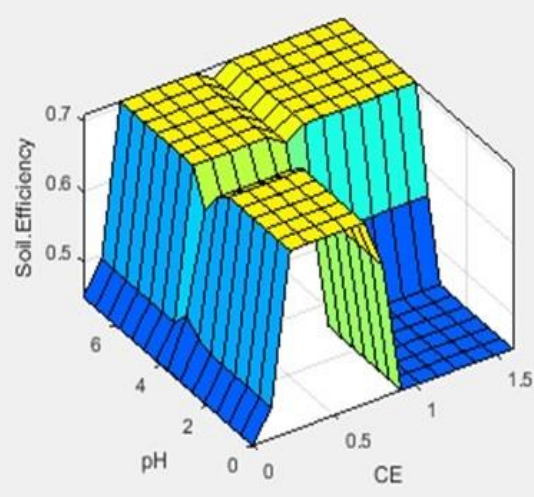

B

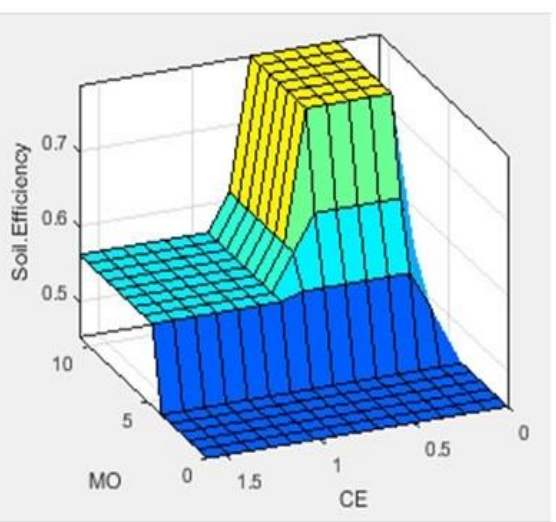

C

Figure 12. Impact of input variables in reactive agent model.

Organic matter makes it possible to reduce problems related to nutrient deficiencies in agricultural soils because organic matter provides the necessary micronutrients $\left(\mathrm{Mg}^{2+}\right.$, $\mathrm{Cu}^{2+}, \mathrm{Fe}^{2+}, \mathrm{Mn}^{2+}$, and $\left.\mathrm{Zn}^{2+}\right)$ to minimize the deficit. The $\mathrm{pH}$ value determines the availability of micronutrients contained in organic matter. Optimal $\mathrm{pH}$ values in agricultural soil 
are between 4.8 and 7.2; $\mathrm{pH}$ values below 4 acidify agricultural soils due to the presence of exchangeable aluminum, altering the development of the crop root and reducing the productivity of sugarcane. As can be seen in Figure 12B, pH values above 4.5 increase the efficiency of soils by values above 0.68 . PH values between 2.8 and 4 result in a soil efficiency below 0.53 . Electrical conductivity is a potential indicator for estimating soil and nutrient properties [71]. Figure $12 \mathrm{C}$ shows the relationship between electrical conductivity and organic matter. The response surfaces show high soil efficiency $(>0.8)$ which is higher than the results obtained in the relationship between organic matter and $\mathrm{pH}$.

For a model to be classified according to the agent approach (ABM), it must be reactive. The reactivity of an intelligent agent refers to the fact that it can analyze the state within the system in which it is immersed to react appropriately to changes caused by the environment [7]. The function of the fuzzy reactive agent model is one of "learning". This is activated to reduce the vulnerability of the crop when vulnerability values above 0.54 are obtained. If the vulnerability values are greater than 0.54 , the reactive agent is activated to reduce the vulnerability (cycles 3,8 , and 10 ). If the vulnerability values are below 0.54 , the reactive agent is inactive. Figure 13 shows the results at the end of the twelve-cycle simulation. As observed, when the cycles exceed the optimal vulnerability levels, the reactive agent activates and decreases by $8 \%( \pm 3 \%)$.

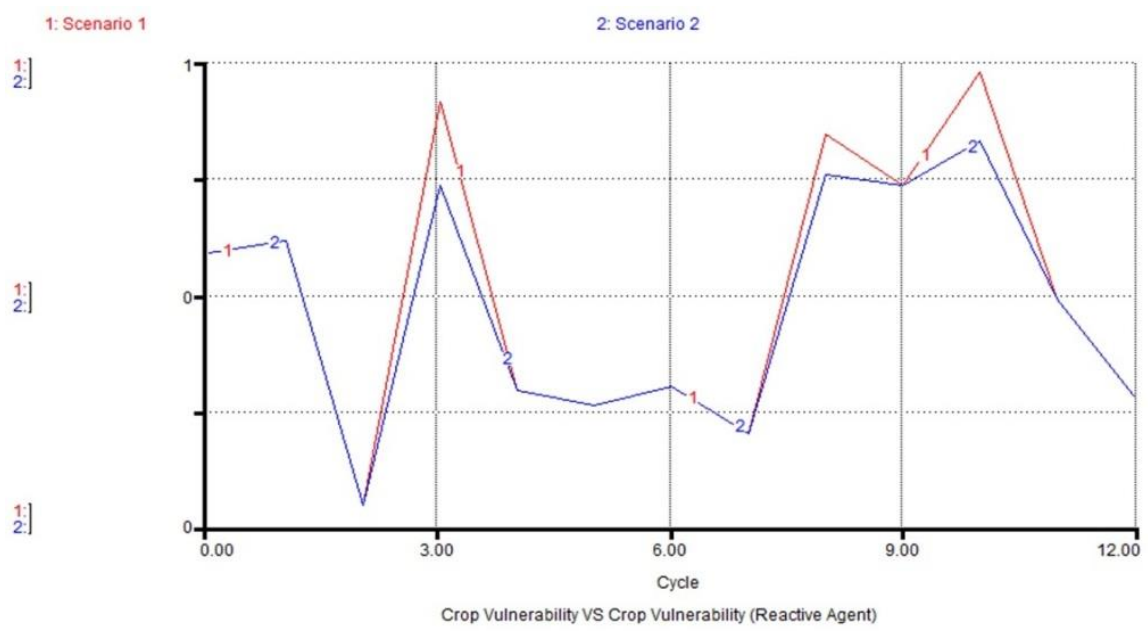

Figure 13. Crop vulnerability vs crop vulnerability (reactive agent).

Table 7 shows the soil efficiency obtained from the diffuse reactive agent model and the results in the vulnerability scenarios over twelve sugarcane cultivation cycles. Scenario 1 shows the results of crop vulnerability from the fuzzy models. In scenario 2 it is observed that the interaction of the reactive agent reduces the vulnerability when it exceeds values of 0.54 . The final vulnerability value for the model is 0.37 , which indicates a low level of vulnerability.

In the multi-agent system, the crop vulnerability agent handles the decision-making process about the reactive agent and the flow of information provided by the agent networks as vulnerability indicators. The vulnerability indicators of the agent network form a decision support system for long-term land development strategies and prospects. 
Table 7. Crop vulnerability results.

\begin{tabular}{cccc}
\hline Cycle & Scenario 1 & Scenario 2 & Reactive Agent \\
\hline 1 & 0.45 & 0.45 & 0.73 \\
2 & 0.22 & 0.22 & 0.79 \\
3 & 0.57 & 0.49 & 0.6 \\
4 & 0.32 & 0.32 & 0.78 \\
5 & 0.3 & 0.3 & 0.74 \\
6 & 0.32 & 0.32 & 0.62 \\
7 & 0.28 & 0.28 & 0.66 \\
8 & 0.54 & 0.5 & 0.81 \\
9 & 0.49 & 0.49 & 0.69 \\
10 & 0.59 & 0.53 & 0.67 \\
11 & 0.4 & 0.4 & 0.78 \\
12 & 0.31 & 0.31 & 0.59 \\
& Final value: Crop vulnerability agent 0.37 & & \\
\hline
\end{tabular}

\section{Step 3: Determination of total vulnerability of the system}

With the results obtained in step 1, a vulnerability factor was assigned to each value obtained (Table 8). The vulnerability weighting for the Agricultural Land Yield and Agricultural Value Networks was determined based on the 2017 Grain Yield and Global Agricultural Value Added by the United Nations Food and Agriculture Organization [72] and the World Bank [39].

Table 8. Vulnerability scale.

\begin{tabular}{|c|c|c|c|c|c|c|}
\hline \multicolumn{2}{|c|}{ Vulnerability } & \multirow{2}{*}{$\begin{array}{c}\begin{array}{c}\text { Land } \\
\text { Yield }\end{array} \\
\begin{array}{c}\text { Value } \\
(\mathrm{Kg} / \mathrm{Ha})\end{array}\end{array}$} & \multirow{2}{*}{$\begin{array}{c}\begin{array}{c}\text { Agriculture } \\
\text { Value }\end{array} \\
\text { Value (\% } \\
\text { GDP) }\end{array}$} & \multirow{2}{*}{$\begin{array}{c}\begin{array}{c}\text { Water } \\
\text { Resources } \\
\text { Efficiency }\end{array} \\
\begin{array}{c}\text { Value } \\
\left(\mathrm{kg} / \mathrm{m}^{3}\right)\end{array}\end{array}$} & \multirow{2}{*}{$\begin{array}{c}\text { GHG } \\
\text { Emissions } \\
\text { Value (Gt } \\
\mathrm{CO}_{2} \text { eq) }\end{array}$} & \multirow{2}{*}{$\begin{array}{c}\text { Emergency or } \\
\text { Risk Situation } \\
\text { Value } \\
\text { (Events) }\end{array}$} \\
\hline Scale & Label & & & & & \\
\hline $0-0.37$ & Low & $>4464$ & $>5.2$ & $>2.2$ & $<60,000$ & $<4100$ \\
\hline $0.38-0.68$ & Medium & $3262-4464$ & $3.4-5.2$ & $1-2.2$ & $60,000-190,000$ & $4100-15,950$ \\
\hline $0.69-1$ & High & $<3262$ & $<3.4$ & $<1$ & $>190,000$ & $>15,950$ \\
\hline
\end{tabular}

The allocation of the vulnerability value for the networks for resource efficiency and environmental contingency (GHG emissions-emergency or risk situation) was carried out based on historical data observed from 2001 to 2018 [43,45,47,48,50,73]. The vulnerability scale for each expected value of the variable of interest is shown below.

Based on the vulnerability scale, Table 9 shows the results at the end of the twelve-cycle simulation; with a final vulnerability value of 0.56 being obtained. Average vulnerability is related to environmental contingency and resource depletion in the agricultural sector which affects crop yield and the value of agriculture. 
Table 9. Vulnerability results (Vulnerability Indicators Agent).

\begin{tabular}{|c|c|c|c|c|c|}
\hline \multirow[b]{2}{*}{ Land Yield } & \multirow[b]{2}{*}{ Agriculture Value } & \multirow[b]{2}{*}{$\begin{array}{l}\text { Water Resources } \\
\text { Efficiency }\end{array}$} & \multicolumn{3}{|c|}{ Environmental Contingency } \\
\hline & & & GHG Emissions & $\begin{array}{l}\text { Emergency or } \\
\text { Risk Situation }\end{array}$ & Final Value \\
\hline 0.58 & 0.89 & 0.59 & 0.58 & 0.43 & 0.49 \\
\hline 0.56 & 0.69 & 0.51 & 0.58 & 0.45 & 0.51 \\
\hline 0.56 & 0.73 & 0.47 & 0.66 & 0.47 & 0.55 \\
\hline 0.53 & 0.38 & 0.46 & 0.67 & 0.47 & 0.55 \\
\hline 0.58 & 0.64 & 0.45 & 0.66 & 0.47 & 0.55 \\
\hline 0.59 & 0.71 & 0.44 & 0.68 & 0.49 & 0.57 \\
\hline 0.55 & 0.64 & 0.42 & 0.67 & 0.48 & 0.56 \\
\hline 0.55 & 0.61 & 0.42 & 0.68 & 0.5 & 0.58 \\
\hline 0.57 & 0.78 & 0.42 & 0.68 & 0.5 & 0.58 \\
\hline 0.56 & 0.73 & 0.4 & 0.68 & 0.5 & 0.58 \\
\hline 0.53 & 0.75 & 0.39 & 0.69 & 0.51 & 0.59 \\
\hline 0.57 & 0.79 & 0.39 & 0.70 & 0.51 & 0.59 \\
\hline \multicolumn{3}{|c|}{ Vulnerability Indicators Agent: 0.56} & & & \\
\hline
\end{tabular}

\section{Discussion}

The results obtained in stages 1 (Table 9) and 2 (Table 7) were used to determine the overall vulnerability of the system, with an average level (0.47) being obtained. The results obtained in Stage 2 showed vulnerability values that were below those obtained in Stage 1; because implementing techniques including response surfaces reduces the number of simulations used to estimate parameters and results [74]. In the multi-agent system, the communication between the agents offers the possibility of interacting with one another as shown in the vulnerability values in stages 1 and 2; As the vulnerability is lower in stage 2, this is an indication that the crop has a low harvest risk due to weather conditions and the good management of the agricultural practices used, which helps to minimize the impact of the external factors mentioned in stage 1.

Autonomy allows the agent to act without the direct intervention of another agent. In this case, the vulnerability indicator agent's performance and the crop yield agent's performance are not interdependent because they are independent, and each agent has its role. However, they work together for the same general objective (stage 3 ) and respond appropriately to changes in the system (reactive agent).

Multi-agent systems can characterize complex study systems [73], which are mainly complex systems that intervene with various actors or agents. Different from other techniques, implementing a multi-agent system for assessing vulnerabilities under the ABM approach provides the following advantages:

i. Dynamism, by examining complex systems, problems at the micro-level are tackled, as there is a connection between cause and effect in the causal diagram (Figure 2) and macro-level, where the relationships between the elementary subsystems are examined.

ii. Flexibility, in this case, the interaction of a reactive agent gives the multi-agent system flexibility to make changes within the system to achieve the goal. In stage 2, the vulnerability can be reduced by performing the reactive agent (non-nutritional disorders model) (Figure 13).

iii. Adaptability. The multi-agent system developed as a generic model serves as the basis for assessing the vulnerability of crops with characteristics similar to sugarcane by varying the dynamic variables of the model concerning the characteristics of the crops and the cultivation area as well as changes in mainly the inference engine of fuzzy models.

For the aforementioned in the discussion section, we can conclude that the contribution to the state of the art and to knowledge is a model based on decision support agents, contributing mainly in the following aspects: 
Model integrated by agro climatic indicators of vulnerability capable of representing structural causes of the system under conditions of uncertainty and dynamism.

The study system is modeled through time series; system dynamics; uncertain parameters; data mining and expertise; facilitating the study; understanding and analysis of the object of study allowing to evaluate different scenarios resulting from variations in the trend in aspects such as agricultural production; and incidence of meteorological phenomena or reduction of resources.

The development and implementation of the agent-based model (ABM) allows the capitalization of knowledge and information through the autonomy and social ability of the agents modeled through artificial intelligence techniques.

The development of the reactive agent showed a decrease in the levels of vulnerability as shown in Table 7; Therefore, the ABM not only seeks the characterization of the system to determine the vulnerability existing in the sugarcane crop, rather, it allows decisions to be made with the objective of minimizing levels of vulnerability in order to increase crop yield and production value.

The validation of the agent-based model, consists of three steps: (i) the dynamic models were verified by calculating the vulnerability indexes for each information network (Figure 2), the results obtained were compared with the vulnerability scale established by the Mexican Institute of Water Technology (IMTA) [48]. (ii) For the validation of the fuzzy logic models, the results obtained in twelve simulation cycles were compared against historical data reported by the case study mill (Figure 7), obtaining a correlation coefficient of 0.9465; finally, (iii) for the validation of the agent model, a qualitative verification of the results obtained from the proposed methodology was carried out through the adaptation schemes for the sugarmill (case study), which were endorsed by the company's agronomists, who considered them consistent with the system's behavior pattern. The implementation of the work schemes will be carried out in the next planting cycle for the year 2022.

\section{Conclusions}

Agricultural systems are anthropogenic ecosystems in continuous evolution that respond not only to climatic but also to socio-economic and institutional changes related to the production process. The loss of biodiversity of crops and fauna and the impact of climate change accelerates the spread of viruses and infectious diseases transmitted from animals to humans, such as COVID-19. Among the factors that increase this condition are deforestation, changes in land use, and excessive agriculture, which affect the agricultural supply chain related to the supply and demand of agricultural products $[75,76]$

The modeling of uncertain parameters enables estimates of behavioral patterns and possible impacts within the system. In this sense, the vulnerability must be analyzed as a systemic and dynamic condition.

Agent-based models (ABM) can analyze and simulate newly occurring properties of the system through the interaction and information flow of virtual agents. The developed $\mathrm{ABM}$ comprises agent networks designed with the help of artificial intelligence techniques that allow the study of the behavior and interactions of the agents who integrate the networks.

The vulnerability indicator agent showed a greater impact on environmental contingency due to the increase in GHG emissions and the exponential growth of meteorological phenomena that endanger the agricultural harvest. Likewise, factors such as crop loss, depletion of resources, and loss of soil fertility jeopardize the proper development of agricultural activities, affecting the value of agriculture and consequently making the agricultural sector more vulnerable. The crop vulnerability agent demonstrated the optimal production conditions in terms of agricultural practices and soil nutrition to achieve a higher yield from the sugarcane crop. The highest expected yield varies between 76 and 81 tons/ha in terms of the variables N-P-K (nitrogen, phosphorus, and potassium) related to soil nutrition. Using fertilizers is critical to the productivity of the plantations; Since it contributes to the nutrient deficiencies in agricultural soil that arise from soil degradation 
or the effects of climate change, counteracting saline effects that inhibit the growth of sugarcane roots.

The reactive agent enables the modeling of physicochemical indicators of the edaphic condition in the supply area of the sugar mill to predict the efficiency of the agricultural soil. In this way, the vulnerability of the harvest is counteracted, and the sugarcane harvest vulnerability is reduced by $8 \%$. Applying the agent-based model, a vulnerability of 0.47 was obtained, which was considered to be moderate.

This research contributes to the state-of-the-art knowledge of a decision support system through an agent-based model to assess the vulnerability of agriculture to sugarcane growing by developing scenarios dynamically and simultaneously to propose work programs leading to the mitigation climatic change of and carry out adaptation measures.

This research provides (i) an agent-based methodology integrated by different techniques for modeling and developing environmental and socioeconomic indicators to generate adaptation schemes for the agricultural system under study facing climate change; and, (ii) models for knowledge and experience management through fuzzy logic and models that allow representing the uncertainty of the system under study by means of system dynamics simulation to obtain socioeconomic indicators. With the methodology and models developed, an agent-based macro-model was obtained to address problems related to crop vulnerability to climate change. The macro-model obtained serves as a generic model, which can be adapted to crops with similar characteristics to sugarcane, management of similar agricultural practices, and edaphic and climatological conditions similar to those in the study area.

Author Contributions: A.A.A.-L. was in charge of project administration and the research related to the application of artificial intelligence techniques. A.E.B.-M. was in charge of the research project related to the application of the agent modeling, dynamic systems and fuzzy logic. A.A.A.-L. and M.A.M.-A. were an advisor of the research and case study. O.O.S.-G., D.V.-V. and R.P.-G. supervision the research and proof-read the paper. All authors have read and agreed to the published version of the manuscript.

Funding: This research received no external funding.

Institutional Review Board Statement: Not Applicable.

Informed Consent Statement: Not Applicable.

Data Availability Statement: Not Applicable.

Acknowledgments: Authors are grateful to CONACYT (the Mexican National Council of Science and Technology) for the scholarship received in the PhD thesis with number (CVU/grant holder): 551429, which was the base of this work and to the Porres Group management for allowing the data collection in its facilities. We thank National Technology of Mexico for funding the project with reference number 10275.21-P entitled "Sistema de Apoyo a la Decisión para la evaluación de vulnerabilidad y riesgo agrícola de la caña de azúcar ante el cambio climático a través de un modelo multi-agentes".

Conflicts of Interest: The authors declare no conflict of interest. 


\section{Appendix A}

Tables A1-A4 describes the parameters used in the design of the model: input variables, constitution of fuzzy sets (linguistic labels and intervals), knowledge base (inference rules) and output variable for the fuzzy models.

Table A1. Crop yiel model: fuzzy sets and operation intervals.

\begin{tabular}{|c|c|c|c|c|c|c|c|c|}
\hline \multicolumn{4}{|c|}{ Input } & \multirow{3}{*}{$\begin{array}{c}\text { Knowledge } \\
\text { Base }\end{array}$} & \multicolumn{4}{|c|}{ Output } \\
\hline \multirow[b]{2}{*}{ Variable } & \multicolumn{3}{|c|}{ Diffuse sets } & & \multirow[b]{2}{*}{ Variable } & \multicolumn{3}{|c|}{ Diffuse Sets } \\
\hline & Label & $\begin{array}{l}\text { Membership } \\
\text { Function }\end{array}$ & Interval & & & Label & $\begin{array}{l}\text { Membership } \\
\text { Function }\end{array}$ & Interval \\
\hline \multirow{2}{*}{ Agriculture Type } & $\begin{array}{c}\text { Open } \\
\text { Agriculture }\end{array}$ & Triangular & {$[1,2]$} & \multirow{20}{*}{$\begin{array}{c}768 \\
\text { Inference } \\
\text { Rules }\end{array}$} & \multirow{20}{*}{ Crop Yield } & \multirow{4}{*}{ None } & \multirow{4}{*}{ Triangular } & \multirow{4}{*}[0,4.4]{} \\
\hline & $\begin{array}{c}\text { Potected } \\
\text { Agriculture }\end{array}$ & Triangular & {$[2,3]$} & & & & & \\
\hline \multirow{2}{*}{ Irrigation } & Rainfall & Triangular & {$[0,1]$} & & & & & \\
\hline & Irrigated & Triangular & {$[1,2]$} & & & & & \\
\hline \multirow{6}{*}{ Irrigation System } & None & Triangular & {$[0,1]$} & & & \multirow{4}{*}{ Lower } & \multirow{4}{*}{ Triangular } & \multirow{4}{*}[1.5,16.3]{} \\
\hline & Gravity & Triangular & {$[1,2]$} & & & & & \\
\hline & Canal & Triangular & {$[2,3]$} & & & & & \\
\hline & Sprinkler & Triangular & {$[3,4]$} & & & & & \\
\hline & Trickle & Triangular & {$[4,5]$} & & & \multirow{4}{*}{ Low } & \multirow{4}{*}{ Trapezoidal } & \multirow{4}{*}[10,46.1]{} \\
\hline & Pipeline & Triangular & {$[5,6.6]$} & & & & & \\
\hline \multirow{2}{*}{$\begin{array}{l}\text { Nitrogen, } \\
\left(\mathrm{Kg} \mathrm{ha}^{-1}\right)\end{array}$} & $\begin{array}{l}\text { Low to } \\
\text { Medium }\end{array}$ & Trapezoidal & {$[0,36.5]$} & & & & & \\
\hline & High & Trapezoidal & {$[25,65]$} & & & & & \\
\hline \multirow{2}{*}{$\begin{array}{l}\text { Phosphorus, }(\mathrm{Kg} \\
\left.\mathrm{P}_{2} \mathrm{O}_{5} \text { ha }^{-1}\right)\end{array}$} & $\begin{array}{l}\text { Low to } \\
\text { Medium }\end{array}$ & Trapezoidal & {$[0,14]$} & & & \multirow{4}{*}{ Medium } & \multirow{4}{*}{ Trapezoidal } & \multirow{4}{*}[38,76]{} \\
\hline & Higher & Trapezoidal & {$[10,25]$} & & & & & \\
\hline \multirow{2}{*}{$\begin{array}{c}\text { Potassium } \\
\left(\mathrm{Kg} \mathrm{K}_{2} \mathrm{O} \text { ha }^{-1}\right)\end{array}$} & Low & Triangular & {$[0,58]$} & & & & & \\
\hline & $\begin{array}{l}\text { Medium to } \\
\text { Higher }\end{array}$ & Trapezoidal & {$[43,200]$} & & & & & \\
\hline & Yes & Triangular & {$[1,2]$} & & & \multirow{4}{*}{ High } & \multirow{4}{*}{ Trapezoidal } & \multirow{4}{*}[65.5,125]{} \\
\hline Pesticide & None & Triangular & {$[0,1]$} & & & & & \\
\hline \multirow{2}{*}{ Insecticide } & Yes & Triangular & {$[1,2]$} & & & & & \\
\hline & None & Triangular & {$\left[\begin{array}{ll}0 & 1\end{array}\right]$} & & & & & \\
\hline
\end{tabular}

Table A2. Uncertain parameters model: fuzzy sets and operation intervals.

\begin{tabular}{|c|c|c|c|c|c|c|c|c|}
\hline \multicolumn{4}{|c|}{ Input } & \multirow{3}{*}{$\begin{array}{c}\text { Knowledge } \\
\text { Base }\end{array}$} & \multicolumn{4}{|c|}{ Output } \\
\hline \multirow[b]{2}{*}{ Variable } & \multicolumn{3}{|c|}{ Diffuse Sets } & & \multirow[b]{2}{*}{ Variable } & \multicolumn{3}{|c|}{ Diffuse sets } \\
\hline & Label & $\begin{array}{l}\text { Membership } \\
\text { Function }\end{array}$ & Interval & & & Label & $\begin{array}{l}\text { Membership } \\
\text { Function }\end{array}$ & Interval \\
\hline \multirow{2}{*}{$\begin{array}{l}\text { Meteorological } \\
\text { Events }\end{array}$} & Warning & Trapezoidal & {$[0,119]$} & \multirow{12}{*}{$\begin{array}{l}72 \text { Inference } \\
\text { Rules }\end{array}$} & \multirow{12}{*}{ Harvest Risk } & \multirow{4}{*}{ Harmless } & \multirow{4}{*}{ Triangular } & \multirow{4}{*}[0,0.43]{} \\
\hline & Emergency & Trapezoidal & {$[95,258]$} & & & & & \\
\hline \multirow{2}{*}{ Drought } & Warning & Trapezoidal & {$[0,117]$} & & & & & \\
\hline & Emergency & Trapezoidal & {$[76,185]$} & & & & & \\
\hline \multirow{3}{*}{$\begin{array}{l}\text { Wind } \\
(\mathrm{Km} / \mathrm{hr})\end{array}$} & Weak & Triangular & {$[0,50]$} & & & \multirow{4}{*}{ Moderate } & \multirow{4}{*}{ Triangular } & \multirow{4}{*}[0.3,0.72]{} \\
\hline & Hard & Triangular & {$[40,60]$} & & & & & \\
\hline & Strong & Trapezoidal & {$[50,100]$} & & & & & \\
\hline \multirow{2}{*}{$\begin{array}{c}\text { Rain } \\
\text { (mm/month) }\end{array}$} & Low Level & Trapezoidal & {$[0,50]$} & & & & & \\
\hline & High Level & Triangular & {$[10,170]$} & & & \multirow{4}{*}{ Risk } & \multirow{4}{*}{ Trapezoidal } & \multirow{4}{*}[0.64,1]{} \\
\hline \multirow{3}{*}{$\begin{array}{c}\text { Temperature } \\
\left({ }^{\circ} \mathrm{C}\right)\end{array}$} & Minimum & Trapezoidal & {$[14,23]$} & & & & & \\
\hline & Optimal & Trapezoidal & {$[18,32]$} & & & & & \\
\hline & Maximum & Trapezoidal & {$[29,43]$} & & & & & \\
\hline
\end{tabular}


Table A3. Crop vulnerability model: fuzzy sets and operation intervals.

\begin{tabular}{|c|c|c|c|c|c|c|c|c|}
\hline \multicolumn{4}{|c|}{ Input } & \multirow{3}{*}{$\begin{array}{l}\text { Knowledge } \\
\text { base }\end{array}$} & \multicolumn{4}{|c|}{ Output } \\
\hline \multirow[b]{2}{*}{ Variable } & \multicolumn{3}{|c|}{ Diffuse sets } & & \multirow[b]{2}{*}{ Variable } & \multicolumn{3}{|c|}{ Diffuse sets } \\
\hline & Label & $\begin{array}{l}\text { Membership } \\
\text { Function }\end{array}$ & Interval & & & Label & $\begin{array}{l}\text { Membership } \\
\text { Function }\end{array}$ & Interval \\
\hline \multirow{2}{*}{$\begin{array}{c}\text { Planted Area } \\
(\mathrm{Ha})\end{array}$} & Low Season & Trapezoidal & {$[6,7354]$} & \multirow{14}{*}{$\begin{array}{l}120 \text { Inference } \\
\text { Rules }\end{array}$} & \multirow{14}{*}{$\begin{array}{l}\text { Crop Vul- } \\
\text { nerability }\end{array}$} & \multirow{4}{*}{ Low } & \multirow{4}{*}{ Triangular } & \multirow{4}{*}[0,0.33]{} \\
\hline & High Season & Trapezoidal & {$[4333,25,000]$} & & & & & \\
\hline \multirow{2}{*}{$\begin{array}{l}\text { Harvest Area } \\
\text { (Ha) }\end{array}$} & Low Harvest & Trapezoidal & {$[3,8187]$} & & & & & \\
\hline & High Harvest & Trapezoidal & {$[4108,23,800]$} & & & & & \\
\hline $\begin{array}{c}\text { Production } \\
\text { Value }\end{array}$ & Expected & Trapezoidal & $\begin{array}{l}{\left[1.59 \times 10^{3}\right.} \\
\left.1.71 \times 10^{7}\right]\end{array}$ & & & & & \\
\hline (Thousands US\$) & High & Trapezoidal & $\begin{array}{l}{\left[1.14 \times 10^{7}\right.} \\
\left.4.73 \times 10^{7}\right]\end{array}$ & & & Medium & Trapezoidal & {$[0.2,0.76]$} \\
\hline \multirow{5}{*}{ Crop Yield } & None & Triangular & {$[0,4.4]$} & & & & & \\
\hline & Lower & Triangular & {$[1.5,16.3]$} & & & & & \\
\hline & Low & Trapezoidal & {$[10,46.1]$} & & & & & \\
\hline & Medium & Trapezoidal & {$[38,76]$} & & & \multirow{5}{*}{ High } & \multirow{5}{*}{ Trapezoidal } & \multirow{5}{*}[0.65,1]{} \\
\hline & High & Trapezoidal & {$[65.5,125]$} & & & & & \\
\hline \multirow{3}{*}{ Harvest Risk } & Harmless & Triangular & {$[0,0.43]$} & & & & & \\
\hline & Moderate & Triangular & {$[0.3,0.72]$} & & & & & \\
\hline & Risk & Trapezoidal & {$[0.64,1]$} & & & & & \\
\hline
\end{tabular}

Table A4. Non-nutritional disorders model: fuzzy sets and operation intervals.

\begin{tabular}{|c|c|c|c|c|c|c|c|c|}
\hline \multicolumn{4}{|c|}{ Input } & \multirow{3}{*}{$\begin{array}{c}\text { Knowledge } \\
\text { Base }\end{array}$} & \multicolumn{4}{|c|}{ Output } \\
\hline \multirow[b]{2}{*}{ Variable } & \multicolumn{3}{|c|}{ Diffuse Sets } & & \multirow[b]{2}{*}{ Variable } & \multicolumn{3}{|c|}{ Diffuse sets } \\
\hline & Label & $\begin{array}{l}\text { Membership } \\
\text { Function }\end{array}$ & Interval & & & Label & $\begin{array}{l}\text { Membership } \\
\text { Function }\end{array}$ & Interval \\
\hline \multirow{2}{*}{$\begin{array}{c}\text { PMP } \\
\text { (Wilting point) }\end{array}$} & Underneath & Triangular & {$[0,28]$} & \multirow{12}{*}{$\begin{array}{l}72 \text { Inference } \\
\text { Rules }\end{array}$} & \multirow{12}{*}{$\begin{array}{c}\text { Soil } \\
\text { Efficiency }\end{array}$} & \multirow{4}{*}{ Optimal } & \multirow{4}{*}{ Trapezoidal } & \multirow{4}{*}[0.55,1]{} \\
\hline & Optimal & Trapezoidal & {$[22,73]$} & & & & & \\
\hline \multirow{3}{*}{$\begin{array}{c}\text { CE } \\
\text { (Electric Conductivity) } \\
\mathrm{dS} / \mathrm{m}\end{array}$} & Min & Trapezoidal & {$[0,0.19]$} & & & & & \\
\hline & Med & Trapezoidal & {$[0.1,0.9]$} & & & & & \\
\hline & Max & Trapezoidal & {$[0.73,1.6]$} & & & \multirow{4}{*}{ Median } & \multirow{4}{*}{ Triangular } & \multirow{4}{*}[0.19,0.72]{} \\
\hline \multirow{3}{*}{$\mathrm{pH}$} & Min & Triangular & {$[0,4.8]$} & & & & & \\
\hline & Med & Triangular & {$[3.5,6.5]$} & & & & & \\
\hline & Max & Triangular & {$[5.4,7.4]$} & & & & & \\
\hline \multirow{2}{*}{$\begin{array}{c}\mathrm{MO} \% \\
\text { (Organic Matter) }\end{array}$} & Medium & Trapezoidal & {$[0,5.7]$} & & & \multirow{4}{*}{ Poor } & \multirow{4}{*}{ Triangular } & \multirow{4}{*}[0,0.28]{} \\
\hline & Maximum & Trapezoidal & {$[4.2,10.8]$} & & & & & \\
\hline \multirow{2}{*}{$\begin{array}{c}\text { Int.Acidity } \\
\text { (Interchangeable } \\
\text { Acidity) } \mathrm{cMol}^{*} \mathrm{Kg}^{-1}\end{array}$} & Medium & Triangular & {$[0,0.22]$} & & & & & \\
\hline & Maximum & Triangular & {$[0.1,0.6]$} & & & & & \\
\hline
\end{tabular}

\section{Appendix B}

Tables A5-A8 describes the input parameters for each fuzzy model: Crop yield, Uncertain parameters, Crop vulnerability and Non-nutritional disorders. 
Table A5. Fuzzy model input parameters: Crop yield.

\begin{tabular}{ccc}
\hline Variable & Value & Unit \\
\hline $\mathrm{V}_{1}$ Agriculture Type & Open Agriculture & Mode \\
$\mathrm{V}_{2}$ Irrigation & Rainfall & Mode \\
$\mathrm{V}_{3}$ Irrigation System & None & Mode \\
$\mathrm{V}_{4}$ Plaguicide & Yes & Aplication \\
$\mathrm{V}_{5}$ Insecticide & Yes & Aplication \\
$\mathrm{V}_{6}$ Nitrogen & 60 & $\mathrm{Kg} \mathrm{ha}^{-1}$ \\
$\mathrm{~V}_{7}$ Phosphorus & 12 & $\mathrm{Kg} \mathrm{P}_{2} \mathrm{O}_{5} \mathrm{ha}^{-1}$ \\
$\mathrm{~V}_{8}$ Potassium & 120 & $\mathrm{Kg} \mathrm{K}_{2} \mathrm{O} \mathrm{ha}^{-1}$ \\
\hline
\end{tabular}

Table A6. Fuzzy model input parameters: uncertain parameters.

\begin{tabular}{ccc}
\hline Variable & Value & Unit \\
\hline $\mathrm{V}_{9}$ Meteorological Events & 35 & Number of events * \\
$\mathrm{V}_{10}$ Drought & 48 & Number of events * \\
$\mathrm{V}_{11}$ Wind & 38 & $\mathrm{Km} / \mathrm{hr}$ \\
$\mathrm{V}_{12}$ Rain & 166 & $\mathrm{~mm} / \mathrm{month}$ \\
$\mathrm{V}_{13}$ Temperature & 27 & ${ }^{\circ} \mathrm{C}$ \\
\hline${ }^{*}$ Tumber
\end{tabular}

* Number of events in the last cycle.

Table A7. Fuzzy model input parameters: crop vulnerability.

\begin{tabular}{ccc}
\hline Variable & Value & Unit \\
\hline $\mathrm{V}_{14}$ Planted Area & 2497 & Ton \\
$\mathrm{V}_{15}$ Harvested Area & 2497 & Ton \\
$\mathrm{V}_{16}$ Production Value & $139,607.67$ & Thousands of $\$$ \\
$\mathrm{O}_{1}$ Crop Yiel & 65.1 & Ton $/$ Ha \\
$\mathrm{O}_{2}$ Harvest Risk & 0.21 & Level \\
\hline
\end{tabular}

Table A8. Fuzzy model input parameters: reactive agent.

\begin{tabular}{ccc}
\hline Variable & Value & Unit \\
\hline $\mathrm{V}_{17}$ Wilting point (PMP) & 23 & PMP Level \\
$\mathrm{V}_{18}$ Electric Conductivity (CE) & 1.6 & $\mathrm{dS} / \mathrm{m}$ \\
$\mathrm{V}_{19} \mathrm{pH}$ & 6.3 & $\mathrm{pH} \mathrm{Level}$ \\
$\mathrm{V}_{20}$ Organic Matter (MO) & 10.3 & $\%$ \\
$\mathrm{~V}_{21}$ Interchangeable Acidity & 0.4 & $\mathrm{cMol}^{*} \mathrm{Kg}^{-1}$ \\
(Int.Acidity) & &
\end{tabular}

\section{References}

1. SAGARPA México. El Sector Agropecuario Ante el Desafío del Cambio Climático; Sagarpa: Mexico City, Mexico, 2012; Volume I, 439p. (In Spanish)

2. Torres Lima, P.; Cruz Castillo, J.G.; Acosta Barradas, R. Vulnerabilidad agroambiental frente al cambio climático. Agendas de adaptación y sistemas institucionales. Política y Cultura 2011, 36, 205-232. (In Spanish)

3. Fowler, H.J.; Kilsby, C.G.; O'Connell, P.E. Modeling the impacts of climatic change and variability on the reliability, resilience, and vulnerability of a water resource system. Water Resour. Res. 2003, 39, 1222. [CrossRef]

4. CONADESUCA. Programa Nacional de la Agroindustria de la Caña de Azúcar; Comité Nacional para el Desarrollo Sustentable de la Caña de Azúcar: Mexico City, Mexico, 2018. (In Spanish)

5. Ritchie, H. Our World in Data. Available online: https://ourworldindata.org/food-ghg-emissions (accessed on 20 September 2012).

6. Matthews, R.B.; Gilbert, N.G.; Roach, A.; Polhill, J.G.; Gotts, N.M. Agent-based land-use models: A review of applications. Landsc. Ecol. 2007, 22, 1447-1459. [CrossRef]

7. Li, J.; Chan, F.T.S. An agent-based model of supply chains with dynamic structures. Appl. Math. Model. 2013, 37, 5403-5413. [CrossRef]

8. Wood, E.C.; Tappan, G.G.; Hadj, A. Understanding the drivers of agricultural land use change in south-central Senegal. J. Arid Environ. 2004, 59, 565-582. [CrossRef] 
9. Araus, J.L.; Slafer, G.A.; Royo, C.; Serret, M.D. Breeding for yield potential and stress adaptation in cereals. Crit. Rev. Plant Sci. 2008, 27, 377-412. [CrossRef]

10. Semenov, M.A.; Halford, N.G. Identifying target traits and molecular mechanisms for wheat breeding under a changing climate. J. Exp. Bot. 2009, 60, 2791-2804. [CrossRef] [PubMed]

11. Barnabás, B.; Jäger, K.; Fehér, A. The effect of drought and heat stress on reproductive processes in cereals. Plant Cell Environ. 2008, 31, 11-38. [CrossRef]

12. Paloviita, A.; Kortetmäki, T.; Puupponen, A.; Silvasti, T. Vulnerability matrix of the food system: Operationalizing vulnerability and addressing food security. J. Clean. Prod. 2016, 135, 1242-1255. [CrossRef]

13. Sain, G.; Loboguerrero, A.M.; Corner-Dolloff, C.; Lizarazo, M.; Nowak, A.; Martínez-Barón, D.; Andrieu, N. Costs and benefits of climate-smart agriculture: The case of the Dry Corridor in Guatemala. Agric. Syst. 2017, 151, 163-173. [CrossRef]

14. Mercure, J.F.; Pollitt, H.; Bassi, A.M.; Viñuales, J.E.; Edwards, N.R. Modelling complex systems of heterogeneous agents to better design sustainability transitions policy. Glob. Environ. Change 2016, 37, 102-115. [CrossRef]

15. Lee, D.R.; Edmeades, S.; De Nys, E.; McDonald, A.; Janssen, W. Developing local adaptation strategies for climate change in agriculture: A priority-setting approach with application to Latin America. Glob. Environ. Change 2014, 29, 78-91. [CrossRef]

16. Salvati, L.; Bajocco, S.; Ceccarelli, T.; Zitti, M.; Perini, L. Towards a process-based evaluation of land vulnerability to soil degradation in Italy. Ecol. Indic. 2011, 11, 1216-1227. [CrossRef]

17. Salomé, C.; Coll, P.; Lardo, E.; Metay, A.; Villenave, C.; Marsden, C.; Blanchart, E.; Hinsinger, P.; Le Cadre, E. The soil quality concept as a framework to assess management practices in vulnerable agroecosystems: A case study in Mediterranean vineyards. Ecol. Indic. 2016, 61, 456-465. [CrossRef]

18. Hofmann, M.E.; Hinkel, J.; Wrobel, M. Classifying knowledge on climate change impacts, adaptation, and vulnerability in Europe for informing adaptation research and decision-making: A conceptual meta-analysis. Glob. Environ. Change 2011, 21, 1106-1116. [CrossRef]

19. Belhouchette, H.; Louhichi, K.; Therond, O.; Mouratiadou, I.; Wery, J.; van Ittersum, M.; Flichman, G. Assessing the impact of the Nitrate Directive on farming systems using a bio-economic modelling Chain. Agric. Syst. 2011, 104, 135-145. [CrossRef]

20. Mitter, H.; Heumesser, C.; Schmid, E. Spatial modeling of robust crop production portfolios to assess agricultural vulnerability and adaptation to climate change. Land Use Policy 2015, 46, 75-90. [CrossRef]

21. Wibowo, S.; Duan, S.X.; Chong, J. A multicriteria analysis approach for evaluating the performance of agriculture decision support systems for sustainable agribusiness. Mathematics 2021, 9, 884. [CrossRef]

22. Sattari, M.T.; Apaydin, H.; Shamshirband, S. Performance evaluation of deep learning-based gated recurrent units (GRUs) and tree-based models for estimating ETo by using limited meteorological variables. Mathematics 2020, 8, 972. [CrossRef]

23. Eza, U.; Shtiliyanova, A.; Borras, D.; Bellocchi, G.; Carrère, P.; Martin, R. An open platform to assess vulnerabilities to climate change: An application to agricultural systems. Ecol. Inform. 2015, 30, 389-396. [CrossRef]

24. Monterroso, A.; Conde, C.; Gay, C.; Gómez, J.; López, J. Indicadores de Vulnerabilidad y Cambio Climático en la Agricultura de México; Centro de Ciencias la Atmósfera e Instituto de Geografia UNAM: Mexico City, Mexico, 2013. (In Spanish)

25. Fourcade, Y. Comparing species distributions modelled from occurrence data and from expert-based range maps. Implication for predicting range shifts with climate change. Ecol. Inform. 2016, 36, 8-14. [CrossRef]

26. Bousquet, F.; Le Page, C. Multi-agent simulations and ecosystem management: A review. Ecol. Modell. 2004, 176, 313-332. [CrossRef]

27. Kremmydas, D.; Athanasiadis, I.N.; Rozakis, S. A review of Agent Based Modeling for agricultural policy evaluation. Agric. Syst. 2018, 164, 95-106. [CrossRef]

28. O'Sullivan, D.; Evans, T.; Manson, S.; Metcalf, S.; Ligmann-Zielinska, A.; Bone, C. Strategic directions for agent-based modeling: Avoiding the YAAWN syndrome. J. Land Use Sci. 2016, 11, 177-187. [CrossRef]

29. Schlüter, M.; Baeza, A.; Dressler, G.; Frank, K.; Groeneveld, J.; Jager, W.; Janssen, M.A.; McAllister, R.R.J.; Müller, B.; Orach, K.; et al. A framework for mapping and comparing behavioural theories in models of social-ecological systems. Ecol. Econ. 2017, 131, 21-35. [CrossRef]

30. Jones, J.W.; Antle, J.M.; Basso, B.; Boote, K.J.; Conant, R.T.; Foster, I.; Godfray, H.C.J.; Herrero, M.; Howitt, R.E.; Janssen, S.; et al. Toward a new generation of agricultural system data, models, and knowledge products: State of agricultural systems science. Agric. Syst. 2017, 155, 269-288. [CrossRef]

31. Yancato Gurmán, J. Intelligent agents. Fiis Uni. Available online: https://www.uv.mx/aguerra/documents/2013-ia2-01.pdf\%0A (accessed on 20 October 2021).

32. Forrester, J. Ingeniero Eléctrico Dinamica-de-Sistemas-¿Qué es la dinámica de sistemas? In Dinámica de Sistemas; Pegasus Communications: Waltham, MA, USA, 1968. (In Spanish)

33. Campuzano-Bolarín, F.; Martínez-Caro, E.; Ros-McDonell, L. Cadenas de suministro tradicionales y colaborativas. DYNA Ingeneria e Industria 2010, 85, 31-38. (In Spanish)

34. Sullivan, C.; Meigh, J. Targeting attention on local vulnerabilities using an integrated index approach: The example of the climate vulnerability index. Water Sci. Technol. 2005, 51, 69-78. [CrossRef] [PubMed]

35. INEGI Encuesta Nacional Agropecuaria. ENA 2017 Conociendo el campo de México Resultados Conferencia de prensa 25 de julio de 2018. 2018. Available online: https://www.inegi.org.mx/contenidos/programas/ena/2017/doc/ena2017_pres.pdf (accessed on 20 October 2021). 
36. CENAPRED Centro Nacional de Prevención de Desastres. Available online: https://www.gob.mx/cenapred (accessed on 20 October 2021).

37. CONAFOR Comisión Nacional Forestal. Available online: https://www.gob.mx/conafor (accessed on 20 October 2021).

38. SMN Servicio Meteorológico Nacional. Available online: https://smn.conagua.gob.mx/es/ (accessed on 20 October 2021).

39. World Bank Indicator. Available online: https:/ / datos.bancomundial.org/indicador/NV.AGR.TOTL.ZS (accessed on 25 September 2019).

40. CONAGUA Comisión Nacional del Agua. Available online: https://smn.conagua.gob.mx/es/climatologia/informacionclimatologica/informacion-estadistica-climatologica (accessed on 20 October 2021).

41. ENA Encuestra Nacional Agropecuaria. Available online: https://datos.gob.mx/busca/dataset/encuesta-nacional-agropecuariaena (accessed on 20 October 2021).

42. INECC Instituto Nacional de Ecología y Cambio Climático. Available online: https://www.gob.mx/inecc (accessed on 20 October 2021).

43. INEGI Instituto Nacional de Estadística Geografía e Información. 2018. Available online: https:/ / www.inegi.org.mx/ (accessed on 20 October 2021).

44. Inifap Instituto Nacional de Investigaciones Forestales Agricolas y Pecuarias. Available online: https://www.gob.mx/inifap (accessed on 20 October 2021).

45. SAGARPA. Programa Sectorial de Desarrollo Agropecuario, Pesquero y Alimentario; SAGARPA: Mexico City, Mexico, 2013.

46. SEMARNAT Secretaría del Medio Ambiente y Recursos Naturales. Available online: https://www.gob.mx/semarnat (accessed on 28 December 2018).

47. SIACON Sistema de Información Agroalimentaria de Consulta. Available online: https://www.gob.mx/siap/documentos/ siacon (accessed on 27 November 2018).

48. CONAGUA. Atlas de Vulnerabilidad Hídrica en México Ante el Cambio Climático; Instituto Mexicano de Tecnología del Agua location: Jiutepec, Mexico, 2015; ISBN 9786079368074. (In Spanish)

49. INEGI PIB y cuentas nacionales. Indicador Global de la Actividad Económica. Available online: https://www.inegi.org.mx/ temas/igae/ (accessed on 9 September 2021).

50. The World Bank. Available online: https://data.worldbank.org/indicator (accessed on 20 October 2021).

51. SIAP Servicio de Información Agroalimentaria y Pesquera. Available online: http://infosiap.siap.gob.mx/gobmx/datosAbiertos. php (accessed on 20 October 2021).

52. Cedillo-Campos, M.G. Análisis Dinámico de Sistemas Industriales, 1st ed.; Trillas: Mexico City, Mexico, 2008; ISBN 978-968-24-8196-3. (In Spanish)

53. Pronac, P.N.d.l.A.d.l.C.d.A.; Siap, S.d.I.A.y.P.; Colpos, C.d.P. Digitalización del Campo Cañero en México para Alcanzar la Agricultura de Precisión de la Caña de Azúcar. Desarrollo de un Modelo Integral de Sistema de Información Geográfica y Edáfica; SAGARPA: Mexico City, Mexico, 2009. (In Spanish)

54. Wedding, D.K. Fuzzy sets and fuzzy logic: Theory and applications. Neurocomputing 1997, 14, 302-303. [CrossRef]

55. Ponce Cruz, P. Inteligencia Artificial con Aplicaciones a la Ingeniería; Alfaomega Grupo Editor: Cuauhtémoc, Mexico, 2010; ISBN 9786077854838. (In Spanish)

56. Zadeh, L.A. Fuzzy logic. In Computational Complexity: Theory, Techniques, and Applications; Springer: Berlin/Heidelberg, Germany, 2013; ISBN 9781461418009.

57. Sivanandam, S.N.; Sumathi, S.; Deepa, S.N. Introduction to Fuzzy Logic Using MATLAB; Springer: Berlin/Heidelberg, Germany, 2007; ISBN 3540357807.

58. PRONAC Programa Nacional de la Agroindustria de la Caña de Azúcar. Available online: http://www.cndsca.gob.mx/ documentoseficproductiva/ 8 (accessed on 26 October 2021).

59. INEGI Encuesta Nacional Agropecuaria ENA 2017 Conociendo el campo de México Resultados Conferencia de prensa 25 de julio de 2018. 2017. Available online: https:/ / www.inegi.org.mx/programas/ena/2017/ (accessed on 9 September 2021).

60. PRONAC/PRONAC 2014-2018.pdf. ENA Encuesta Nacional Agrícola. Available online: https://www.inegi.org.mx/programas/ ena/2019/ (accessed on 9 September 2021).

61. SIAP Servicio de Información Agroalimentaria y Pesquera. Available online: https://www.gob.mx/siap (accessed on 20 October 2021).

62. Sterling, L.S.; Taveter, K. The Art of Agent-Oriented Modeling; MIT Press: Cambridge, MA, USA, 2018.

63. Stockdale, E.A.; Watson, C.A. Biological indicators of soil quality in organic farming systems. Renew. Agric. Food Syst. 2009, 24, 308-318. [CrossRef]

64. Grimm, V.; Railsback, S. Individual-Based Modeling and Ecology (Princeton Series in Theoretical and Computational Biology); Princeton University Press: Princeton, NJ, USA, 2005; ISBN 069109666X.

65. Forrester, J.W.; Senge, P.M. Tests for building confidence in system dynamics models. TIMS Stud. Manag. Sci. 1980, 14, 209-228.

66. Pérez-Pérez, C.S.; Nieto-Barajas, L.E. Hierarchical Analysis of Greenhouse Gas Emissions in Mexico. REALITY DATA Sp. Int. J. Stat. Geogr. 2019, 10, 3.

67. Reilly, J.; Prinn, R.; Harnisch, J.; Fitzmaurice, J.; Jacoby, H.; Kicklighter, D.; Melillo, J.; Stone, P.; Sokolov, A.; Wang, C. Multi-gas assessment of the Kyoto protocol. Nature 1999, 401, 549-555. [CrossRef] 
68. Inegi Instituto Nacional de Geografía y Estadística. Available online: https:/ / www.inegi.org.mx/temas/pib/ (accessed on 20 September 2009).

69. Dieguez Cameroni, F.J.; Terra, R.; Tabarez, S.; Bommel, P.; Corral, J.; Bartaburu, D.; Pereira, M.; Montes, E.; Duarte, E.; Morales Grosskopf, H. Virtual experiments using a participatory model to explore interactions between climatic variability and management decisions in extensive grazing systems in the basaltic region of Uruguay. Agric. Syst. 2014, 130, 89-104. [CrossRef]

70. Holman, I.P.; Brown, C.; Janes, V.; Sandars, D. Can we be certain about future land use change in Europe? A multi-scenario, integrated-assessment analysis. Agric. Syst. 2017, 151, 126-135. [CrossRef]

71. Mauricio, S.; Peralta, N.; Costa, J.L. Relationship between apparent electrical conductivity with soil properties and nutrients. Cienc. del Suelo 2013, 31, 45-55.

72. Food and Agriculture Organization Indicator. Available online: https://datos.bancomundial.org/indicador/AG.YLD.CREL.KG? view $=$ chart (accessed on 21 October 2019).

73. Pino, R.; Fernandez, I.; de la Fuente, D.; Parreño, J.; Priore, P. Supply chain modelling using a multi-agent system. J. Adv. Manag. Res. 2010, 7, 149-162. [CrossRef]

74. Berger, T.; Troost, C. Agent-based Modelling of Climate Adaptation and Mitigation Options in Agriculture. J. Agric. Econ. 2014, 65, 323-348. [CrossRef]

75. Zuniga, B.G.L.; Calderon, K.; Ale, T.M.L. Impacts of COVID-19 on agriculture and food security. Cent. Agric. 2021, 48, 72-82

76. Lacy-Niebla, M.D.C. Climate change and the COVID-19 pandemic. Arch. Cardiol. Mex. 2021, 91, 269-271. [CrossRef] 